\title{
Novel semisynthetic derivatives of betulin and betulinic acid with cytotoxic activity
}

\author{
Rita C. Santos ${ }^{\mathrm{a}}$, Jorge A. R. Salvador ${ }^{\mathrm{a}, *}$, Silvia Marín ${ }^{\mathrm{b}}$, Marta Cascante ${ }^{\mathrm{b}, *}$ \\ a Laboratório de Química Farmacêutica, Faculdade de Farmácia, Universidade de Coimbra, Polo das Ciências da Saúde, Azinhaga de Santa Comba, $3000-548$ Coimbra, Portugal \\ ${ }^{\mathrm{b}}$ IBUB-Department of Biochemistry and Molecular Biology, Faculty of Biology, Universitat de Barcelona, Avda. Diagonal 645, Barcelona 08028, Spain
}

\section{A R T I C L E I N F O}

\section{Article history:}

Received 23 May 2009

Accepted 22 July 2009

Available online 25 July 2009

\section{Keywords:}

Triterpenoids

Betulinic acid

Imidazole

Cytotoxicity

\begin{abstract}
A B S T R A C T
A series of new imidazole carboxylic esters (carbamates) and $\mathrm{N}$-acylimidazole derivatives of betulin and betulinic acid (14-29) have been synthesized. The new compounds were screened for in vitro cytotoxicity activity against human cancer cell lines HepG2, Jurkat and HeLa. A number of compounds have shown $\mathrm{IC}_{50}$ values lower than $2 \mu \mathrm{M}$ against the cancer cell lines tested and the vast majority has shown a better cytotoxicity profile than betulinic acid, including the betulin derivatives. $N$-Acylimidazole derivatives $\mathbf{2 6}$ and 27 (IC I0 $_{0} 0.8$ and $1.7 \mu \mathrm{M}$ in HepG2 cells) and the C-3 carbamate derivative $\mathbf{1 6}$ (IC $502.0 \mu \mathrm{M}$ in HepG2 cells) were the most promising compounds. Based on the observed cytotoxicity, structure-activity relationships have been established.
\end{abstract}

(c) 2009 Elsevier Ltd. All rights reserved.

\section{Introduction}

Cancer is the second most important disease leading to death in both the developing and developed countries nowadays. Numerous experimental and epidemiological studies have shown that several plant derived natural products may serve as effective anticancer drugs, among which are plant triterpenes, for example betulin and betulinic acid. ${ }^{1,2}$ Betulin $\mathbf{1}$ is a main component of birch bark, ${ }^{3}$ and can be synthetically converted to betulinic acid $\mathbf{2}$ in a two-step procedure, in high yield. ${ }^{4}$ Both $\mathbf{1}$ and $\mathbf{2}$ (Fig. 1 ) were reported to display several biological effects including anti-inflammatory, antiviral, antimalarial and in particular anticancer., ${ }^{5,6}$ Previous reports revealed that compound $\mathbf{2}$ is a melanoma-specific cytotoxic agent, ${ }^{7}$ however recent evidence has indicated that $\mathbf{2}$ possesses a broader spectrum of cytotoxic activity against other cancer types. ${ }^{8-11}$ Moreover, compound 2 has been suggested to induce apoptosis via the activation of caspases, regardless of cellular p53 gene status and CD95 activation. ${ }^{12,13}$ This apoptosis inducing ability, the apparent lack of toxicity on normal cells, ${ }^{14}$ and the favourable therapeutic index have made $\mathbf{2}$ an attractive and a very promising anticancer agent. ${ }^{15}$

This lupane triterpene is currently undergoing clinical trials at the National Cancer Institute (NCI). ${ }^{16}$ Nevertheless, the poor aqueous solubility of lupane triterpenes such as $\mathbf{2}$, which compromises blood serum solubilization, has limited the exploitation of their po-

\footnotetext{
* Corresponding authors. Tel.: +351 239488479; fax: +351 239827126 (J.A.R.S.); tel.: +34 9340215 9; fax: +34934021219 (M.C.).

E-mail addresses: salvador@ci.uc.pt (J.A.R. Salvador), martacascante@ub.edu (M. Cascante).
}

tential in both the medical and pharmaceutical areas. ${ }^{17}$ For this reason a huge amount of effort has been directed towards performing modifications of $\mathbf{2}$ in order to increase and broaden its range of biological activities. In contrast to $\mathbf{2}$, compound $\mathbf{1}$ has no significant cytotoxic activity. ${ }^{18,19}$ However, some derivatives were found to be active. ${ }^{19,20}$

The structures of $\mathbf{1}$ and $\mathbf{2}$ consist of a 30-carbon skeleton which has three available sites for simple chemical modifications at C-3, $\mathrm{C}-20$ and $\mathrm{C}-28$. Modifications of the parent structure of these compounds at these positions can produce potentially important derivatives, found to be more effective than the starting ones, thus making them appealing for further development as antitumour drugs. ${ }^{18,20-36}$ Nitrogen-containing derivatives of $\mathbf{1}$ and $\mathbf{2}$, such as

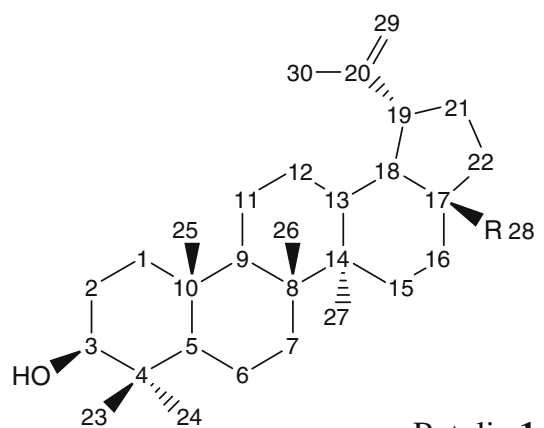

Betulin 1: $\mathrm{R}=\mathrm{CH}_{2} \mathrm{OH}$ Betulinic acid 2: $\mathrm{R}=\mathrm{COOH}$

Figure 1. Chemical structure of betulin $\mathbf{1}$ and betulinic acid $\mathbf{2}$. 
amine derivatives, ${ }^{21,23,35}$ oxime derivatives, ${ }^{21,23,30}$ amino acid conjugates, ${ }^{22}$ amide derivatives, ${ }^{20,32}$ hydrazine ${ }^{29}$ and hydrazone derivatives, ${ }^{28-30,35}$ imidazolide derivatives, ${ }^{37}$ and other $\mathrm{N}$-heterocyclic derivatives ${ }^{24,31,34,36}$ have been reported to possess antiproliferative effect against tumour cell lines.

In the last few years several carbamates have been synthesized as anticancer agents either in the form of drugs per se or as prodrugs. Some carbamates inhibit endothelial cell proliferation in vitro and tumour induced angiogenesis in vivo as well as tumour growth in mice. ${ }^{38}$ Recently, C17 steroidal methylimidazolyl carbamates have been reported to possess antiproliferative effects against prostate cancer cell lines. ${ }^{39}$

Herein we describe the synthesis and in vitro biological evaluation of novel lupane imidazole carbamates and $\mathrm{N}$-acylimidazole derivatives, based on the reaction of the commercially available $1,1^{\prime}$-carbonyldiimidazole (CDI) with the alcohol and carboxylic acid functions of compounds 1, 2 and several derivatives. All new analogs were tested for cytotoxic activity against HepG2 (human hepatocellular carcinoma), Jurkat (human leukemia) and HeLa (human cervical adenocarcinoma) cancer cell lines in order to obtain a preliminary biological profile of this series of compounds that will be useful for future design and development of other derivatives. ${ }^{40}$

\section{Results and discussion}

\subsection{Chemistry}

The general procedure for the synthesis of the 16 novel lupane derivatives 14-29 (Table 1, Schemes 1 and 2) involved dissolution of the corresponding lupanes and CDI, in THF at reflux, under $\mathrm{N}_{2}$. The reaction of CDI with alcohols and phenols has been reported to afford either $N$-alkylimidazoles ${ }^{41-47}$ or imidazole carboxylic esters (carbamates), ${ }^{39,41,42,48-50}$ depending both on alcohol type and on the reaction conditions used. In our case the reaction afforded the lupane carbamates 14-25 and $\mathbf{2 9}$ in good yields. On the other hand the reaction of CDI with the carboxylic acid function of lupane substrates afforded the $\mathrm{N}$-acylimidazoles 26-28 (Scheme 2) which was in accordance with previous results. ${ }^{51-53}$

Due to the fact that the reactivity of the hydroxyl group at C-28 is much higher than that of $\mathrm{C}-3$, the $\mathrm{C}-28$ lupane carbamate $\mathbf{1 4}$ could be directly prepared by using mild reaction conditions. In order to synthesize the C-3 lupane carbamate 16, compound 15 was previously prepared according the general procedure with $\mathrm{CDI}$, and was then selective hydrolyzed at C-28 with silica gel (Table 1) and purified by flash column chromatography (FCC) to afford 16, in $68 \%$ yield. For the synthesis of compounds 19 and 20, the corresponding acetylated substrates were prepared (Table 1). Compound $\mathbf{1}$ was converted into the 28 -monoacetate 3 in $78 \%$ yield by treatment with acetic anhydride and 2 equiv of imidazole, whereas the 3-monoacetate 4 was prepared by a selective hydrolysis of betulin diacetate 6 with methanolic potassium hydroxide, in 74\% yield, according to a known procedure. ${ }^{54}$ Derivative 21 was prepared in $88 \%$ yield from methyl ester $\mathbf{5}$ that was obtained from the reaction of compound $\mathbf{2}$ with methyl iodide in the presence of $\mathrm{K}_{2} \mathrm{CO}_{3}$ (Table 1 ).

The synthesis of derivatives 22 and $\mathbf{2 3}$ (Scheme 1) began with the methoxylation of the isopropenyl group of the commercially available compound $\mathbf{1}$ in two steps, as previously described. ${ }^{31}$ In the first step the reaction of betulin diacetate $\mathbf{6}$ with $\mathrm{N}$-bromosuccinimide (NBS) in $\mathrm{CCl}_{4}$ produced a 30 -bromo derivative which was further hydrolyzed by $\mathrm{NaOH}(4 \mathrm{M})$ in a $\mathrm{MeOH}$ :THF mixture, at room temperature, to afford the 30-methoxy derivative $\mathbf{7}$ and the 30-bromo compound 8. The ratio of compounds $\mathbf{7}$ and $\mathbf{8}$ was dependent on the reaction conditions used. An increase in the hydrolysis time caused an increase in the amount of the
Table 1

Betulin 1 and betulinic acid 2 derivatives 14-21

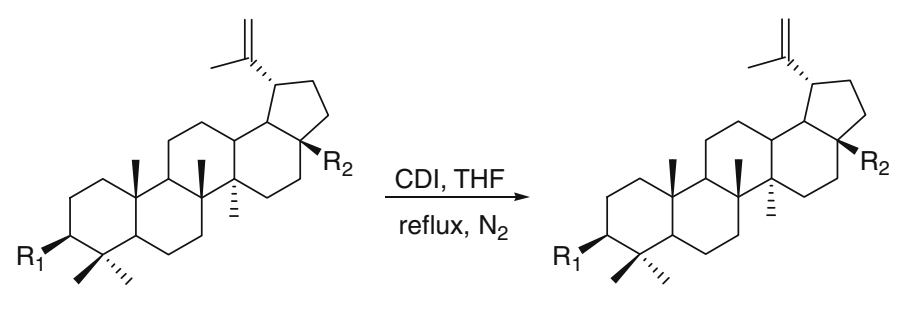

$\mathrm{R}_{1} \quad \mathrm{R}_{2}$

$\mathrm{R}_{1}$

$\mathrm{R}_{2}$

$\mathrm{OH}$

$\mathrm{CH}_{2} \mathrm{OH}$

14

$\mathrm{OH}$

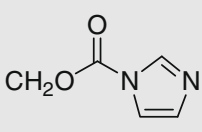

$\mathrm{OH}$

$\mathrm{CH}_{2} \mathrm{OH}$
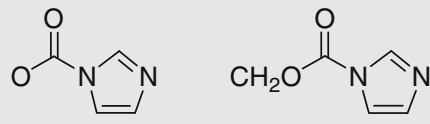

$\mathrm{OH}$

$\mathrm{CH}_{2} \mathrm{OH}$

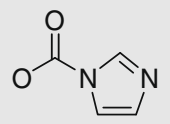

$\mathrm{CH}_{2} \mathrm{OH}$

$\mathrm{OH}$

$\mathrm{COOH}$

17

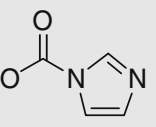

$\mathrm{COOH}$

2

$\mathrm{OH}$

$\mathrm{COOH}$
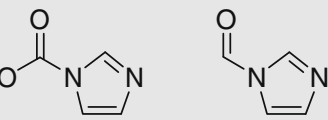

3

$\mathrm{OH}$

$\mathrm{CH}_{2} \mathrm{OAC}$

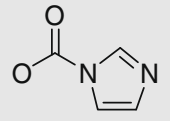

$\mathrm{CH}_{2} \mathrm{OAC}$

4

OAc

$\mathrm{CH}_{2} \mathrm{OH}$

20

OAC

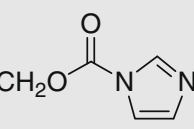

$\mathrm{OH}$

COOMe

21

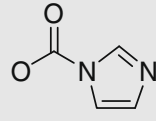

COOMe

30-methoxy derivative 7. This compound was then treated with CDI in THF, at reflux, to afford $\mathbf{2 2}$ and $\mathbf{2 3}$ in 68\% and 28\% yield, respectively, after FCC. For the synthesis of compounds $\mathbf{2 4}$ and $\mathbf{2 5}$, previous to the introduction of the carbamate moieties at $\mathrm{C}-3$ and $\mathrm{C}-28$, compound $\mathbf{1}$ was epoxidized with $m$-chloroperbenzoic acid ( $m$-CPBA), followed by acid catalyzed epoxy ring opening to afford the epimeric isomers (20R-aldehyde) $\mathbf{9}$ (39\%) and (20S-aldehyde) $\mathbf{1 0}(20 \%)$ as major products (Scheme 1$)$. The downfield shift values of the $\mathrm{H}-20$ and $\mathrm{H}-30$ signals on the ${ }^{1} \mathrm{H}$ NMR spectra of compound 9 bearing the 20R configuration ( $\delta 9.86$ and $\delta 1.10 \mathrm{ppm}$ ) and compound 10 bearing the $20 S$ configuration ( $\delta 9.62$ and $\delta$ $1.04 \mathrm{ppm}$ ) are characteristic and are consistent with data reported on the literature. ${ }^{55}$

For the synthesis of derivative 27, betulonic acid $\mathbf{1 1}$ was dehydrated with 2,3-dichloro-5,6-dicyanobenzoquinone (DDQ) in dioxane according to the known method (Scheme 2) ${ }^{56}$ Compound 12 


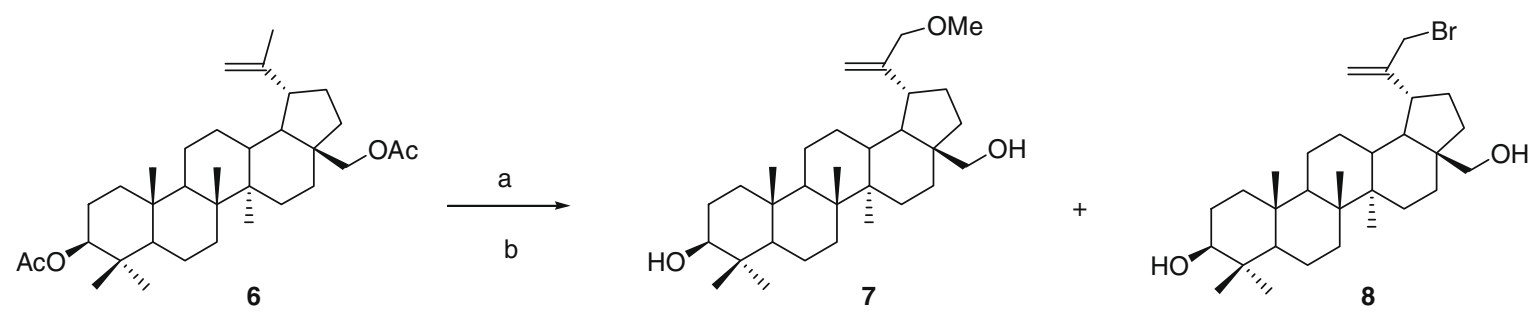

6<smiles>C1CCCCC1</smiles><smiles>C=C(COC)[C@H]1CC[C@]2(COC(=O)n3ccnc3)CC[C@]3(C)C(CCC4[C@@]5(C)CC[C@@H](O)C(C)(C)[C@@H]5CC[C@]43C)C12</smiles>

22<smiles>C=C(COC)[C@H]1CCC2(COC(=O)n3ccnc3)CC[C@]3(C)C(CCC4[C@@]5(C)CC[C@H](OC(=O)n6ccnc6)C(C)(C)C5CC[C@]43C)C12</smiles><smiles>C=C(C)[C@H]1CCC2(CO)CC[C@]3(C)C(CCC4C5(C)CC[C@H](O)C(C)(C)C5CCC43C)C12</smiles><smiles>C1CCCCC1</smiles><smiles>CC(C=O)[C@H]1CC[C@]2(CO)CC[C@]3(C)C(CCC4C3(C)CCC3C(C)(C)[C@@H](O)CC[C@]34C)C12</smiles><smiles>CC(C=O)[C@H]1CCC2(CO)CC[C@]3(C)C(CCC4[C@@]5(C)CC[C@H](O)C(C)(C)[C@H]5CC[C@]43C)C12</smiles>

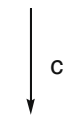

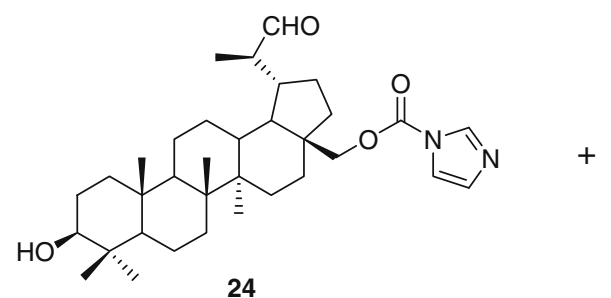

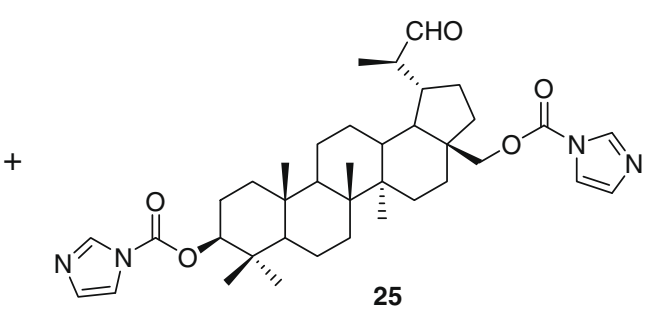

Scheme 1. Synthesis of derivatives 22-25. Reagents and conditions: (a) NBS, CCl 4 , reflux, 3 h; (b) NaOH aq (4 N), MeOH, THF, rt, 29 h; (c) CDI, dry THF, N2, reflux, 7-8 h; (d) $m$ CPBA, $\mathrm{CH}_{2} \mathrm{Cl}_{2}, 0-5^{\circ} \mathrm{C}, 5 \mathrm{~h}$; (e) $\mathrm{H}_{2} \mathrm{SO}_{4}(2 \mathrm{M}), 0-5^{\circ} \mathrm{C}, 1 \mathrm{~h}$.

was then treated with CDI to afford $\mathbf{2 7}$, in $82 \%$ yield. A previously published procedure using oxygen in the presence of potassium tert-butoxide $(t$-BuOK) was used for the preparation of the diosphenol 13 as major product $(72 \%) .{ }^{57}$ Further reaction with CDI and purification by FCC led to the derivatives $\mathbf{2 8}$ and $\mathbf{2 9}$, in $70 \%$ and $30 \%$ yield, respectively (Scheme 2 ).

Full structural elucidation of the new lupane derivatives was made using IR, NMR and MS spectroscopy, and assignments were performed based on our analysis and related literature. The presence of a carbamate moiety on the new derivatives 14-25 and 29 was supported by a strong band at $1751-1762 \mathrm{~cm}^{-1}$ on the IR spectrum that corresponded to the $\mathrm{C}=\mathrm{O}$ stretching vibration. Three ${ }^{1} \mathrm{H}$ NMR peaks at $\delta 8.12-8.29 \mathrm{ppm}, \delta 7.41-7.53 \mathrm{ppm}$ and $\delta 7.05-$ $7.15 \mathrm{ppm}$, typical for the imidazole $\mathrm{H}-2, \mathrm{H}-5$ and $\mathrm{H}-4$ on the imidazole carbamates were found as well as a quaternary ${ }^{13} \mathrm{C}$ NMR signal at $\delta 147.9-149.1 \mathrm{ppm}$ that was assigned as the carbamate carbonyl carbon (OCO). ${ }^{42}$

\subsection{Antiproliferative activity}

It was been reported that a carbonyl group at position C-17 was important for the cytotoxic activity of lupane derivatives. ${ }^{25,27}$ In the light of this, new lupane imidazole carbamates and $\mathrm{N}$-acylimidazoles with one or two carbonyl groups were synthesized.

To evaluate the anticancer potency of these synthesized compounds, the cytotoxic activity of derivatives 14, 17, 22, 24 and 28 was first screened at concentration of $20 \mu \mathrm{M}$ against eight human cancer cell lines of different origin: MCF-7 (breast adenocarcinoma), HepG2 (hepatocellular carcinoma), A-375 (melanoma), HT-29 (colon adenocarcinoma), HeLa (cervical adenocarcinoma), 


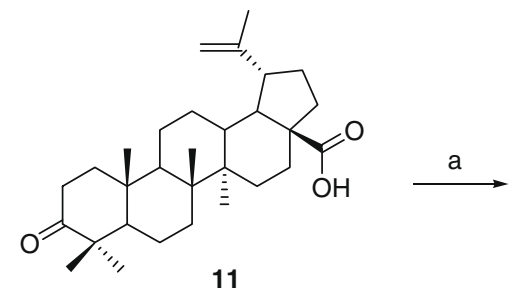<smiles>C=C(C)[C@@H]1CCC2(C(=O)n3ccnc3)CC[C@]3(C)C(CCC4[C@@]5(C)CCC(=O)C(C)(C)C5CC[C@]43C)C12</smiles>

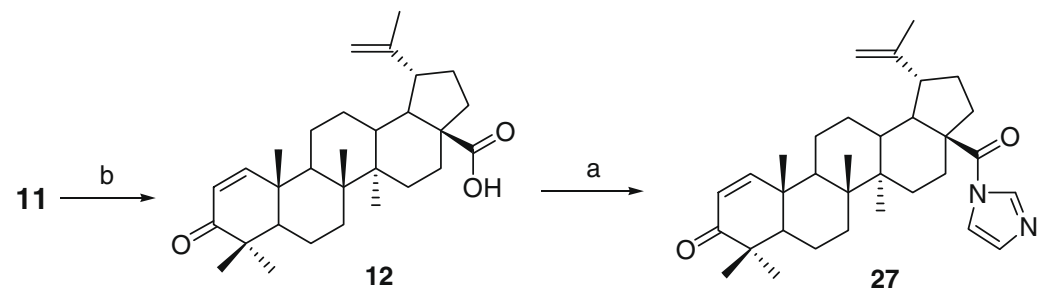

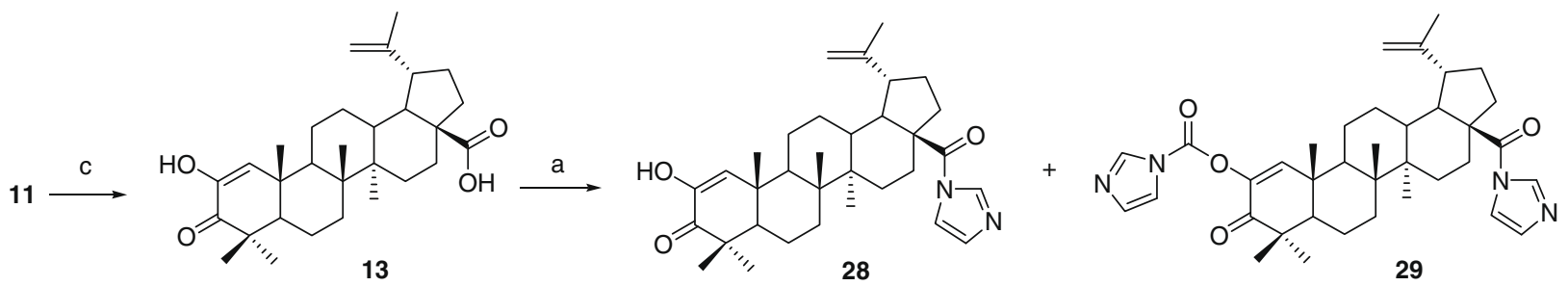

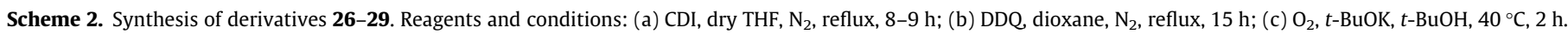

MIA PaCa-2 (pancreas adenocarcinoma), SH-SY5Y (neuroblastoma) and Jurkat (leukemia) (Fig. 2). Although compound 2 has been reported to be preferentially effective against melanoma and neuroectodermal tumours, the synthesized derivatives tested in this study have demonstrated a broad cytotoxicity activity. The percentages of cell proliferation as compared to control indicated that the different compounds were more potent against HepG2, HeLa and Jurkat cell lines. These three cancer cell lines were further used for the determination of the potential of all the new derivatives to inhibit tumour cell proliferation (Table 2). This potential antitumoural effect was tested estimating the concentration at which tumour cell proliferation was inhibited by $50 \%$, after $72 \mathrm{~h}$ of treatment with the compounds. Compound $\mathbf{2}$ was used as positive control. As shown in Table 2, analysis of the $\mathrm{IC}_{50}$ values revealed

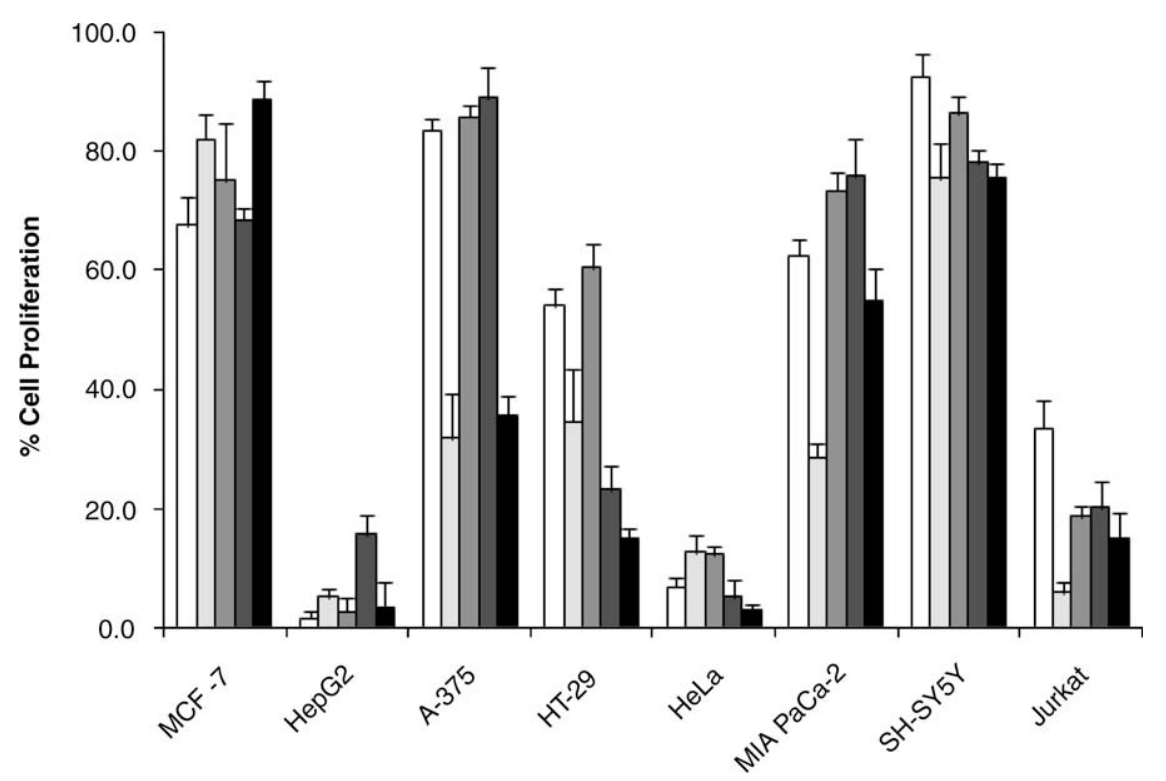

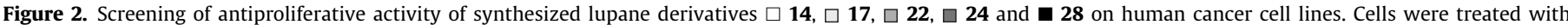

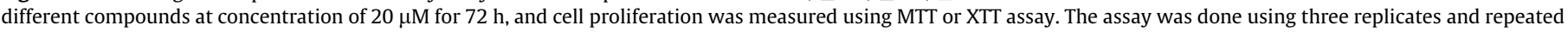
three times. 
Table 2

Cytotoxic activity data for compounds 14-29 against HepG2, Jurkat and HeLa

\begin{tabular}{rllll}
\hline Entry & Compound & \multicolumn{3}{c}{$\mathrm{IC}_{50}{ }^{\mathrm{a}}(\mu \mathrm{M} \pm \mathrm{SD})$} \\
\cline { 3 - 5 } & & HepG2 & Jurkat & HeLa \\
\hline 1 & $\mathbf{2}$ & $36.4 \pm 1.5$ & $26.9 \pm 2.2$ & $26.0 \pm 2.1$ \\
2 & $\mathbf{1 4}$ & $4.2 \pm 0.3$ & $16.3 \pm 1.2$ & $7.6 \pm 0.6$ \\
3 & $\mathbf{1 5}$ & $>30$ & $>30$ & $>30$ \\
4 & $\mathbf{1 6}$ & $2.0 \pm 0.4$ & $11.1 \pm 1.3$ & $3.0 \pm 0.2$ \\
5 & $\mathbf{1 7}$ & $6.2 \pm 0.2$ & $5.2 \pm 0.7$ & $5.1 \pm 0.3$ \\
6 & $\mathbf{1 8}$ & $2.9 \pm 0.4$ & $6.0 \pm 1.2$ & $8.2 \pm 0.4$ \\
7 & $\mathbf{1 9}$ & $>30$ & $>30$ & $>30$ \\
8 & $\mathbf{2 0}$ & 430 & $>30$ & $>30$ \\
9 & $\mathbf{2 1}$ & $8.3 \pm 0.4$ & $12.2 \pm 1.3$ & $8.2 \pm 0.5$ \\
10 & $\mathbf{2 2}$ & $19.6 \pm 1.6$ & $16.2 \pm 1.0$ & $>30$ \\
11 & $\mathbf{2 3}$ & $11.5 \pm 1.1$ & $13.7 \pm 1.4$ & $11.1 \pm 1.4$ \\
12 & $\mathbf{2 4}$ & $26.1 \pm 1.1$ & $20.2 \pm 1.6$ & $19.2 \pm 1.5$ \\
13 & $\mathbf{2 5}$ & $0.8 \pm 0.05$ & $1.4 \pm 0.2$ & $2.0 \pm 0.3$ \\
14 & $\mathbf{2 6}$ & $1.7 \pm 0.2$ & $2.3 \pm 0.3$ & $3.0 \pm 0.2$ \\
15 & $\mathbf{2 7}$ & $6.5 \pm 0.4$ & $7.0 \pm 1.6$ & $4.6 \pm 0.7$ \\
16 & $\mathbf{2 8}$ & $4.0 \pm 0.3$ & $8.1 \pm 0.6$ & $3.9 \pm 0.3$ \\
17 & $\mathbf{2 9}$ & &
\end{tabular}

Exponentially growing cells were treated with the compounds at different concentrations for $72 \mathrm{~h}$. Cell-growth inhibition was analysed by the MTT (HepG2 and HeLa) or XTT (Jurkat) assay. The assay was done using three replicates and repeated four times.

${ }^{\text {a }} \mathrm{IC}_{50}$ is the concentration of compound that inhibits $50 \%$ of cell growth.

that the synthesized derivatives markedly inhibited the proliferation of all the tested cancer cell lines and were particularly effective against the hepatoma HepG2 cell line.

The majority of the novel compounds, 14, 16-18 and 21-29, (Table 2, entries 2, 4-6 and 9-17) showed improved cytotoxic activity against the three tested tumoural cell lines when compared to compound $\mathbf{2}$ (Table 2, entry 1 ), compound $\mathbf{2 6}$ being particularly active (Table 2 , entry 14 ) and 45,19 and 13 -fold more potent than compound $\mathbf{2}$ (Table 2, entry 1 ) towards HepG2, Jurkat and HeLa cell lines, respectively. The acetyl derivatives 19 and 20 (Table 2, entries 7 and 8 ) and the disubstituted derivative $\mathbf{1 5}$ (Table 2, entry 3 ) showed higher $\mathrm{IC}_{50}$ values than compound $2(>30 \mu \mathrm{M})$, which is consistent with the reported data for the in vitro antitumour activity of acetyl derivatives of $1 .{ }^{18}$ The fact that betulonic acid derivatives $\mathbf{2 6}$ and $\mathbf{2 7}$ (Table 2, entries 14 and 15) were the most active compounds showed that oxidation of the hydroxyl group to a ketone at C-3 markedly influenced the cytotoxic potential. The introduction of the carbamate moiety at position C-3 in compounds 15, 23 and 25 (Table 2, entries 3, 11 and 13) resulted in a loss of cytotoxicity in all the tested cell lines when compared with compounds 14, 22 and 24 (Table 2, entries 2, 10 and 12), suggesting a size limitation at position $\mathrm{C}-3$. Moreover, the loss of antiproliferative activity of compounds $\mathbf{2 2}$ and $\mathbf{2 3}$ (Table 2, entries 10 and 11) modified at C-30, and $\mathbf{2 4}$ and 25 (Table 2, entries 12 and 13) modified at C-20, indicated that the cytotoxic profile of derivatives of compound $\mathbf{1}$ may be sensitive to the size and electronic density of the substituents at C-20, and supports the idea that the $\mathrm{C}-20$ position of compounds $\mathbf{1}$ and $\mathbf{2}$ is not a favourable site to modify in order to improve antitumoural activity. ${ }^{23}$

Compounds 18 and 21 (Table 2, entries 6 and 9) inhibited HepG2 cell proliferation at lower concentrations than compound 17 (Table 2, entry 5), which confirmed that the carbonyl group and not the carboxyl group was essential for the cytotoxic activity of the lupane derivatives. ${ }^{25}$

\section{Conclusions}

A large number of structural modifications of compounds $\mathbf{1}$ and 2 as possible antitumour agents were studied. This investigation demonstrates that the incorporation of an imidazole scaffold at the C-28 or C-3 position of compounds $\mathbf{1}$ and $\mathbf{2}$ to obtain carbamates or $\mathrm{N}$-acylimidazoles can produce a number of potentially important derivatives with improved cytotoxic activity. Modifications of the less potent compound $\mathbf{1}$ can lead to derivatives with a better cytotoxicity profile as shown with derivatives 14, 16, 22 and 24. Compounds 16, 26 and 27 are potential lead compounds for new anti-tumour agent development and have been selected for further studies.

\section{Experimental}

\subsection{Chemistry}

\subsubsection{General}

Betulin 1, betulinic acid 2, CDI, NBS, $\mathrm{NaOH}, m-\mathrm{CPBA}, \mathrm{H}_{2} \mathrm{SO}_{4}$, DDQ, $t$-BuOK and tert-butyl alcohol $(t-\mathrm{BuOH})$ were purchased from Sigma Aldrich Co., whereas solvents were obtained from VWR Portugal. For thin layer chromatography (TLC) analysis Kieselgel $60 \mathrm{HF}_{254} /$ Kieselgel $60 \mathrm{G}$ was used and FCC was performed using Kieselgel 60 (230-400 mesh, Merk). Melting points were determined using a BUCHI melting point B-540 apparatus and are uncorrected. IR spectra were obtained using a JASCO FT/IR-420 spectrophotometer. NMR spectra were recorder on a Bruker Digital NMR-Avance 300 apparatus and on a Bruker Digital NMR-Avance 400 apparatus in $\mathrm{CDCl}_{3}$ with $\mathrm{Me}_{4} \mathrm{Si}$ as the internal standard. Elucidation of the chemical structures was based on ${ }^{1} \mathrm{H},{ }^{13} \mathrm{C}$, DEPT135, COSY, HMQC and HMBC NMR experiments. Chemical shifts values $(\delta)$ are given in ppm and the coupling constants $(J)$ are presented in hertz. Mass spectra were obtained using a Finnigan Polaris Q GC/MS Benchtop Ion Trap mass spectrometer with a direct insertion probe.

4.1.1.1. 3及-Hydroxylup-20(29)-en-28-yl acetate (3). Details of the synthesis of this compound were reported previously. ${ }^{54} \mathrm{Com}-$ pound 3 (323 mg, 84\%): IR (film) $v_{\max } 3471,3070,1734,1642$, $1244,1102,880 \mathrm{~cm}^{-1} ;{ }^{1} \mathrm{H}$ NMR $\left(\mathrm{CDCl}_{3}, 300 \mathrm{MHz}\right) \delta 4.69(\mathrm{~s}, 1 \mathrm{H}$, $\left.\mathrm{H}-29_{\mathrm{a}}\right), 4.59$ (s, 1H, H-29b), 4.24 (d, $\left.J=10.9 \mathrm{~Hz}, 1 \mathrm{H}, \mathrm{H}-28_{\mathrm{a}}\right), 3.86$ (d, $\left.J=10.9 \mathrm{~Hz}, 1 \mathrm{H}, \mathrm{H}-28_{\mathrm{b}}\right), 3.18$ (dd, $J=11.0 \mathrm{~Hz}, J=4.7 \mathrm{~Hz}, 1 \mathrm{H}, \mathrm{H}-$ $3 \alpha$ ), 2.45 (dt, $J=10.9 \mathrm{~Hz}, J=5.8 \mathrm{~Hz}, 1 \mathrm{H}, \mathrm{H}-19$ ), 2.07 (s, 3H, $\mathrm{OCOCH}_{3}$ ), $1.68(\mathrm{~s}, 3 \mathrm{H}, \mathrm{H}-30), 1.03(\mathrm{~s}, 3 \mathrm{H}), 0.97(\mathrm{~s}, 3 \mathrm{H}), 0.96(\mathrm{~s}, 3 \mathrm{H}), 0.82(\mathrm{~s}$, $3 \mathrm{H}), 0.76(\mathrm{~s}, 3 \mathrm{H}) ;{ }^{13} \mathrm{C} \mathrm{NMR}\left(\mathrm{CDCl}_{3}, 75 \mathrm{MHz}\right) \delta 171.6\left(\mathrm{OCOCH}_{3}\right)$, 150.2 (C20), 109.9 (C29), 78.9 (C3), 62.8 (C28); EI-MS m/z (\% rel. intensity): 484 (12) $\mathrm{M}^{+}, 203$ (54), 189 (100), 187 (71), 147 (46), 145 (49), 133 (67), 119 (61), 105 (69), 91 (56).

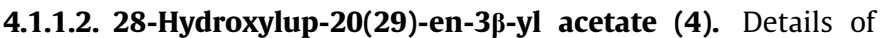
the synthesis of this compound were reported previously. ${ }^{54} \mathrm{Com}-$ pound 4 (259 mg, 89\%): IR (film) $v_{\max } 3440,3070,1729,1642$, 1246, 978, $882 \mathrm{~cm}^{-1} ;{ }^{1} \mathrm{H} \mathrm{NMR}\left(\mathrm{CDCl}_{3}, 300 \mathrm{MHz}\right) \delta 4.68(\mathrm{~s}, 1 \mathrm{H}, \mathrm{H}-$ $29 \mathrm{a}), 4.58\left(\mathrm{~s}, 1 \mathrm{H}, \mathrm{H}-29_{\mathrm{b}}\right), 4.47$ (dd, $J=10.3 \mathrm{~Hz}, J=5.7 \mathrm{~Hz}, 1 \mathrm{H}$, $\mathrm{H}-3 \alpha$ ), 3.79 (d, $J=10.6 \mathrm{~Hz}, 1 \mathrm{H}, \mathrm{H}-28_{\mathrm{a}}$ ), 3.33 (d, $J=10.7 \mathrm{~Hz}, 1 \mathrm{H}, \mathrm{H}-$ $\left.28_{\mathrm{b}}\right), 2.39(\mathrm{dt}, J=10.7 \mathrm{~Hz}, J=5.9 \mathrm{~Hz}, 1 \mathrm{H}, \mathrm{H}-19), 2.04(\mathrm{~s}, 3 \mathrm{H}$, $\left.\mathrm{OCOCH}_{3}\right), 1.69(\mathrm{~s}, 3 \mathrm{H}, \mathrm{H}-30), 1.02(\mathrm{~s}, 3 \mathrm{H}), 0.97(\mathrm{~s}, 3 \mathrm{H}), 0.85(\mathrm{~s}$, $6 \mathrm{H}), 0.84(\mathrm{~s}, 3 \mathrm{H}) ;{ }^{13} \mathrm{C} \mathrm{NMR}\left(\mathrm{CDCl}_{3}, 75 \mathrm{MHz}\right) \delta 171.1\left(\mathrm{OCOCH}_{3}\right)$, 150.5 (C20), 109.7 (C29), 80.9 (C3), 60.5 (C28); EI-MS m/z (\% rel. intensity): 484 (9) $\mathrm{M}^{+}, 203$ (71), 189 (100), 187 (55), 107 (61), 105 (52), 95 (77), 91 (67), 81 (60), 79 (85).

4.1.1.3. Methyl 3ß-hydroxylup-20(29)-en-28-oate (5). To a solution of compound 2 (150 $\mathrm{mg}, 0.33 \mathrm{mmol})$ and anhydrous $\mathrm{K}_{2} \mathrm{CO}_{3}(115 \mathrm{mg}, 0.83 \mathrm{mmol})$ in dry DMF $(2 \mathrm{ml})$ was added methyl iodide $(41 \mu \mathrm{l}, 0.66 \mathrm{mmol})$. The mixture was stirred at room temperature for $1 \mathrm{~h}$. After reaction completion the reaction mixture was diluted in ethyl acetate $(30 \mathrm{ml})$ and washed with water $(3 \times 20 \mathrm{ml})$ and brine $(20 \mathrm{ml})$. The organic phase was dried with anhydrous $\mathrm{Na}_{2} \mathrm{SO}_{4}$, filtered and concentrated under reduced 
pressure to give a yellowish solid. This solid was crystallized from methanol to yield compound 5 (129 mg, 83\%): IR (film) $v_{\max } 3320$, $3070,1720,1643 \mathrm{~cm}^{-1} ;{ }^{1} \mathrm{H}$ NMR $\left(\mathrm{CDCl}_{3}, 300 \mathrm{MHz}\right) \delta 4.71(\mathrm{br} \mathrm{s}, 1 \mathrm{H}$, $\mathrm{H}-29_{\mathrm{a}}$ ), 4.58 (br s, 1H, H-29 ), 3.67 (s, 3H, $\mathrm{COOCH}_{3}$ ), 3.18 (dd, $1 \mathrm{H}$, $J=10.9 \mathrm{~Hz}, J=4.5 \mathrm{~Hz}, \mathrm{H}-3 \alpha) 2.43(\mathrm{~m}, 1 \mathrm{H}, \mathrm{H}-19), 1.69$ (s, 3H, H30), $0.96(\mathrm{~s}, 3 \mathrm{H}), 0.94(3 \mathrm{H}), 0.92(\mathrm{~s}, 3 \mathrm{H}), 0.82(\mathrm{~s}, 3 \mathrm{H}), 0.75(\mathrm{~s}, 3 \mathrm{H})$;

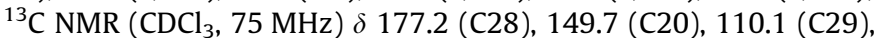
80.6 (C3); EI-MS $m / z$ (\% rel. intensity): 470 (25) M+, 286 (26), 253 (52), 247 (29), 203 (36), 192 (100), 189 (100), 175 (64), 119 (47), 105 (51).

4.1.1.4. Lup-20(29)-en-3ß,28-di-yl acetate (6). Details of the synthesis of this compound were reported previously..$^{54}$ Compound 6 (373 mg, 89\%): IR (film) $v_{\max } 3073,1735,1642,1241,880 \mathrm{~cm}^{-1}$; ${ }^{1} \mathrm{H} \mathrm{NMR}\left(\mathrm{CDCl}_{3}, 300 \mathrm{MHz}\right) \delta 4.69$ (br s, $\left.1 \mathrm{H}, \mathrm{H}-29_{\mathrm{a}}\right) 4.59$ (br s, $1 \mathrm{H}, \mathrm{H}-$ 29 b), 4.47 (dd, $J=10.3 \mathrm{~Hz}, J=5.8 \mathrm{~Hz}, 1 \mathrm{H}, \mathrm{H}-3 \alpha), 4.25$ (d, $J=11.1 \mathrm{~Hz}$, $1 \mathrm{H}, \mathrm{H}-28_{\mathrm{a}}$ ), 3.85 (d, $J=11.1 \mathrm{~Hz}, 1 \mathrm{H}, \mathrm{H}-28_{\mathrm{b}}$ ), 2.45 (dt, $J=10.9 \mathrm{~Hz}$, $J=5.8 \mathrm{~Hz}, 1 \mathrm{H}, \mathrm{H}-19), 2.07\left(\mathrm{~s}, 3 \mathrm{H}, \mathrm{OCOCH}_{3}\right), 2.04\left(\mathrm{~s}, 3 \mathrm{H}, \mathrm{OCOCH}_{3}\right)$, 1.68 (s, 3H, H-30), 1.03 (s, 3H), 0.97 (s, 3H), $0.84(\mathrm{~s}, 6 \mathrm{H}), 0.83$ (s, $3 \mathrm{H}) ;{ }^{13} \mathrm{C} \mathrm{NMR}\left(\mathrm{CDCl}_{3}, 75 \mathrm{MHz}\right) \delta 171.6\left(\mathrm{OCOCH}_{3}\right), 171.0\left(\mathrm{OCOCH}_{3}\right)$, 150.1 (C20), 109.9 (C29), 80.9 (C3), 62.8 (C28); EI-MS m/z (\% rel. intensity): 526 (5) $\mathrm{M}^{+}, 466$ (72), 216 (46), 203 (47), 202 (44), 190 (53), 189 (100), 187 (68), 119 (47), 91 (51).

4.1.1.5. 30-Methoxylup-20-(29)-en-3 $\beta, 28-d i o l \quad(7)$ and 30 bromolup-20(29)-en-3ß,28-diol (8). Details of the synthesis of these compounds were reported previously. ${ }^{31}$ Compound $\mathbf{7}$ (1.4 g, 64\%): IR (film) $v_{\max } 3347,3073,1645 \mathrm{~cm}^{-1} ;{ }^{1} \mathrm{H} \mathrm{NMR}\left(\mathrm{CDCl}_{3}\right.$, $300 \mathrm{MHz}) \delta 4.92\left(\mathrm{~s}, 1 \mathrm{H}, \mathrm{H}-29_{\mathrm{a}}\right), 4.91$ (s, $\left.1 \mathrm{H}, \mathrm{H}-29_{\mathrm{b}}\right), 3.86$ (br s, $2 \mathrm{H}$, $\mathrm{H}-30$ ), 3.78 (d, $J=10.5 \mathrm{~Hz}, 1 \mathrm{H}, \mathrm{H}-28_{\mathrm{a}}$ ), 3.35 (s, 3H, $\left.\mathrm{OCH}_{3}\right), 3.31$ (d, $J=10.5 \mathrm{~Hz}, 1 \mathrm{H}, \mathrm{H}-28_{\mathrm{b}}$ ), 3.18 (dd, $J=10.8 \mathrm{~Hz}, J=5.2 \mathrm{~Hz}, 1 \mathrm{H}, \mathrm{H}-3 \alpha$ ), 2.28 (dt, $J=10.8 \mathrm{~Hz}, J=5.4 \mathrm{~Hz}, 1 \mathrm{H}, \mathrm{H}-19) 1.02$ (s, 3H), 0.98 (s, $3 \mathrm{H}), 0.97(\mathrm{~s}, 3 \mathrm{H}), 0.82(\mathrm{~s}, 3 \mathrm{H}), 0.76(\mathrm{~s}, 3 \mathrm{H}) ;{ }^{13} \mathrm{C} \mathrm{NMR}\left(\mathrm{CDCl}_{3}\right.$, $75 \mathrm{MHz}$ ) $\delta 150.9$ (C20), 109.0 (C29), 78.9 (C3), 74.8 (C30), 60.2 (C28), $58.3\left(\mathrm{OCH}_{3}\right)$; EI-MS $m / z$ (\% rel. intensity): $473(25) \mathrm{M}^{+}, 201$ (93), 189 (86), 187 (100), 145 (75), 131 (66), 121 (71), 119 (73), 95 (66), 81 (69). Compound 8 (451 mg, 18\%): IR (film) $v_{\max } 3371$, $3075,1642 \mathrm{~cm}^{-1} ;{ }^{1} \mathrm{H}$ NMR $\left(\mathrm{CDCl}_{3}, 300 \mathrm{MHz}\right) \delta 5.12(\mathrm{~s}, 1 \mathrm{H}, \mathrm{H}-$ 29a), 5.03 (s, 1H, H-29b), 3.99 (s, 2H, H-30), 3.81 (d, $J=10.8 \mathrm{~Hz}$, $1 \mathrm{H}, \mathrm{H}-28_{\mathrm{a}}$ ), 3.33 (d, $J=10.8 \mathrm{~Hz}, 1 \mathrm{H}, \mathrm{H}-28_{\mathrm{b}}$ ), 3.19 (dd, $J=10.9 \mathrm{~Hz}$, $J=5.1 \mathrm{~Hz}, 1 \mathrm{H}, \mathrm{H}-3 \alpha), 2.39(\mathrm{dt}, J=11.0 \mathrm{~Hz}, J=5.3 \mathrm{~Hz}, 1 \mathrm{H}, \mathrm{H}-19)$ $1.03(\mathrm{~s}, 3 \mathrm{H}), 0.99(\mathrm{~s}, 3 \mathrm{H}), 0.97(\mathrm{~s}, 3 \mathrm{H}), 0.82(\mathrm{~s}, 3 \mathrm{H}), 0.76(\mathrm{~s}, 3 \mathrm{H})$; ${ }^{13} \mathrm{C}$ NMR $\left(\mathrm{CDCl}_{3}, 75 \mathrm{MHz}\right) \delta 151.0$ (C20), 109.8 (C29), 78.9 (C3), 60.3 (C28). EI-MS m/z (\% rel. intensity): 522 (3) $\mathrm{M}^{+}, 121$ (74), 119 (91), 107 (85), 105 (82), 93 (84), 91 (91), 81 (84), 79 (100), 67 (82).

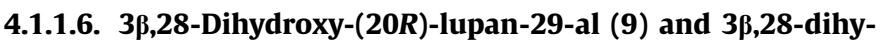
droxy-(20S)-lupan-29-al (10). Details of the synthesis of these compounds were reported previously. ${ }^{55,58}$ Compound 9 (354 mg, 39\%): IR (film) $v_{\max } 3393,1714 \mathrm{~cm}^{-1} ;{ }^{1} \mathrm{H} \mathrm{NMR}\left(\mathrm{CDCl}_{3}, 300 \mathrm{MHz}\right)$ $\delta 9.86(\mathrm{~d}, J=2.0 \mathrm{~Hz}, 1 \mathrm{H}, \mathrm{H}-29), 3.77\left(\mathrm{~d}, J=10.8 \mathrm{~Hz}, 1 \mathrm{H}, \mathrm{H}-28_{\mathrm{a}}\right.$ ), $3.26\left(\mathrm{~d}, J=10.8 \mathrm{~Hz}, 1 \mathrm{H}, \mathrm{H}-28_{\mathrm{b}}\right.$ ), 3.20 (dd, $J=10.9 \mathrm{~Hz}, J=5.1 \mathrm{~Hz}$, $1 \mathrm{H}, \mathrm{H}-3 \alpha) 2.60$ (m, 1H, H-20), 1.10 (d, $J=6.9 \mathrm{~Hz}, 3 \mathrm{H}, \mathrm{H}-30), 1.03$ (s, 3H), $0.98(\mathrm{~s}, 3 \mathrm{H}), 0.95(\mathrm{~s}, 3 \mathrm{H}), 0.84(\mathrm{~s}, 3 \mathrm{H}), 0.77(\mathrm{~s}, 3 \mathrm{H}) ;{ }^{13} \mathrm{C}$ NMR ( $\left.\mathrm{CDCl}_{3}, 75 \mathrm{MHz}\right) \delta 206.8$ (CHO), 78.9 (C3), 60.2 (C28); EI-MS $\mathrm{m} / \mathrm{z}$ (\% rel. intensity): 458 (2) $\mathrm{M}^{+}, 369$ (100), 207 (43), 192 (51), 189 (72), 161 (67), 133 (31), 121 (31), 107 (36), 95 (33). Compound 10 (179 mg, 20\%): IR (film) $v_{\max } 3340,1716 \mathrm{~cm}^{-1} ;{ }^{1} \mathrm{H} \mathrm{NMR}\left(\mathrm{CDCl}_{3}\right.$, $300 \mathrm{MHz}) \delta 9.62$ (s, 1H, H-29), 3.80 (d, J=10.8 Hz, H-28a), 3.33 (d, $\left.J=10.8 \mathrm{~Hz}, 1 \mathrm{H}, \mathrm{H}-28_{\mathrm{b}}\right), 3.20(\mathrm{dd}, J=10.9 \mathrm{~Hz}, J=5.1 \mathrm{~Hz}, 1 \mathrm{H}, \mathrm{H}-3 \alpha)$, $2.65(\mathrm{~m}, 1 \mathrm{H}, \mathrm{H}-20), 1.06(\mathrm{~s}, 3 \mathrm{H}), 1.04(\mathrm{~d}, J=7.0 \mathrm{~Hz}, 3 \mathrm{H}, \mathrm{H}-30)$, 0.98 (s, 6H), 0.84 (s, 3H), 0.77 (s, 3H); ${ }^{13} \mathrm{C}$ NMR $\left(\mathrm{CDCl}_{3}, 75 \mathrm{MHz}\right) \delta$ 204.8 (CHO), 78.9 (C3), 60.2 (C28); EI-MS $\mathrm{m} / \mathrm{z}$ (\% rel. intensity): 458 (4) M+, 369 (76), 207 (48), 190 (46), 189 (100), 161 (70), 119 (51), 105 (46), 95 (47), 91 (59).
4.1.1. 3-0xolup-20(29)-en-28-oic acid (11). Details of the synthesis of this compound were reported previously. ${ }^{4}$ Compound $\mathbf{1 1}$ (685 mg, 67\%): IR (film) $v_{\max } 3070,1703,1686,1642 \mathrm{~cm}^{-1} ;{ }^{1} \mathrm{H}$ NMR $\left(\mathrm{CDCl}_{3}, 300 \mathrm{MHz}\right) \delta 4.77$ (br s, $\left.1 \mathrm{H}, \mathrm{H}-29_{\mathrm{a}}\right), 4.64$ (br s, $1 \mathrm{H}, \mathrm{H}-$ 29 b), 3.04 (dt, $J=10.7 \mathrm{~Hz}, J=4.3 \mathrm{~Hz}, 1 \mathrm{H}, \mathrm{H}-19), 1.72$ (s, 3H, H-30), 1.09 (s, 3H), $1.04(\mathrm{~s}, 3 \mathrm{H}), 1.02(\mathrm{~s}, 3 \mathrm{H}), 0.99(\mathrm{~s}, 3 \mathrm{H}), 0.95(\mathrm{~s}, 3 \mathrm{H}) ;{ }^{13} \mathrm{C}$ NMR $\left(\mathrm{CDCl}_{3}, 75 \mathrm{MHz}\right) \delta 218.2$ (C3), 182.2 (C28), 150.3 (C20), 109.7 (C29); EI-MS $m / z$ (\% rel. intensity): 454 (19) $\mathrm{M}^{+}, 408$ (24), 393 (20), 248 (85), 189 (100), 175 (62), 133 (55), 119 (76), 105 (69), 79 (52).

4.1.1.8. 3-Oxolup-1,20(29)-dien-28-oic acid (12). A solution of compound 11 (400 mg, $0.88 \mathrm{mmol}$ ) and DDQ (597 mg, $2.64 \mathrm{mmol}$ ) in anhydrous dioxane $(18 \mathrm{ml})$ was heated under reflux and $\mathrm{N}_{2}$ atmosphere for $15 \mathrm{~h}$. After the reaction mixture was diluted in ethyl acetate $(60 \mathrm{ml})$ and the insoluble matter was removed by filtration. The filtrate was washed with saturated solution of $\mathrm{Na}_{2} \mathrm{CO}_{3}$ $(3 \times 30 \mathrm{ml})$, and then with water $(30 \mathrm{ml})$ and brine $(30 \mathrm{ml})$, dried with anhydrous $\mathrm{Na}_{2} \mathrm{SO}_{4}$, filtered and concentrated under reduced pressure to give a yellowish solid. This solid was submitted to FCC with petroleum ether $40-60^{\circ} \mathrm{C} /$ ethyl acetate $(4: 1)$ to afford compound 12 (179 mg, 45\%); IR (film) $v_{\max } 3070,1730,1689$ $1645 \mathrm{~cm}^{-1}$; ${ }^{1} \mathrm{H} \mathrm{NMR}\left(\mathrm{CDCl}_{3}, 400 \mathrm{MHz}\right) \delta 7.11(\mathrm{~d}, J=10.3 \mathrm{~Hz}, 1 \mathrm{H}$, $\mathrm{H}-1), 5.80$ (d, $J=10.3 \mathrm{~Hz}, 1 \mathrm{H}, \mathrm{H}-2), 4.76$ (s, 1H, H-29a), 4.63 (s, $\left.1 \mathrm{H}, \mathrm{H}-29_{\mathrm{b}}\right), 3.03(\mathrm{~m}, 1 \mathrm{H}, \mathrm{H}-19), 1.70(\mathrm{~s}, 3 \mathrm{H}, \mathrm{H}-30), 1.13(\mathrm{~s}, 3 \mathrm{H})$ $1.07(\mathrm{~s}, 3 \mathrm{H}), 1.06(\mathrm{~s}, 3 \mathrm{H}), 1.02(\mathrm{~s}, 3 \mathrm{H}), 0.99(\mathrm{~s}, 3 \mathrm{H}) ;{ }^{13} \mathrm{C} \mathrm{NMR}\left(\mathrm{CDCl}_{3}\right.$, $100 \mathrm{MHz}) \delta 205.9$ (C3), 181.7 (C28), 160.1 (C1), 150.2 (C20), 125.1 (C2), 109.9 (C29); EI-MS m/z (\% rel. intensity): 452 (17) $\mathrm{M}^{+}, 213$ (100), 150 (39), 137 (34), 95 (31), 91 (42), 81 (36), 79 (41), 77 (29), 67 (34).

4.1.1.9. 2-Hydroxy-3-oxolup-1,20(29)-dien-28-oic acid (13). Details of the synthesis of these compounds were reported previously. ${ }^{57}$ Compound 13 (273 mg, 73\%): $v_{\max } 3389,3073,1730$, $1698,1669,1645 \mathrm{~cm}^{-1} ;{ }^{1} \mathrm{H}$ NMR $\left(\mathrm{CDCl}_{3}, 300 \mathrm{MHz}\right) \delta 6.45(\mathrm{~s}, 1 \mathrm{H}, \mathrm{H}-$ 1), 4.75 (s, 1H, H-29a ), 4.64 (s, 1H, H-29b), 3.02 (m, 1H, H-19), 1.70 $(\mathrm{s}, 3 \mathrm{H}, \mathrm{H}-30), 1.20(\mathrm{~s}, 3 \mathrm{H}), 1.13(\mathrm{~s}, 3 \mathrm{H}), 1.10(\mathrm{~s}, 3 \mathrm{H}), 1.00(\mathrm{~s}, 3 \mathrm{H})$, $0.98(\mathrm{~s}, 3 \mathrm{H}) ;{ }^{13} \mathrm{C}$ NMR $\left(\mathrm{CDCl}_{3}, 75 \mathrm{MHz}\right) \delta 201.2(\mathrm{C} 3), 182.4$ (C28), 150.1 (C20), 143.9 (C2), 128.9 (C1), 109.9 (C29); EI-MS m/z (\% rel. intensity): 469 (11) $\mathrm{M}^{+}, 321$ (43), 213 (100), 189 (32), 150 (45), 136 (29), 91 (63), 80 (34), 75 (54), 69 (65).

4.1.1.10. 3ß-Hydroxy-lup-20(29)-en-28-yl-1H-imidazole-1-carboxylate (14) and lup-20(29)-en-3ß,28-di-yl-(1H-imidazole-1carboxylate) (15). To a solution of compound 1 (200 mg, $0.45 \mathrm{mmol})$ in anhydrous THF $(8 \mathrm{ml})$, CDI $(219 \mathrm{mg}, 1.35 \mathrm{mmol})$ was added. After $7 \mathrm{~h}$ under magnetic stirring at reflux temperature and $\mathrm{N}_{2}$ atmosphere, the reaction was completed as verified by TLC control. The reaction mixture was poured onto water $(30 \mathrm{ml})$ and extracted with diethyl ether $(3 \times 30 \mathrm{ml})$. The combined organic extract was then washed with water $(30 \mathrm{ml})$, and brine $(30 \mathrm{ml})$, dried with anhydrous $\mathrm{Na}_{2} \mathrm{SO}_{4}$, filtered and concentrated under reduced pressure to give a yellowish solid. This solid was submitted to FCC with petroleum ether $40-60{ }^{\circ} \mathrm{C} /$ ethyl acetate $(3: 2)$ and afforded compound 14 (152 mg, 63\%): mp (acetone) $202-204{ }^{\circ} \mathrm{C}$; IR (film) $v_{\max } 3570,3078,1751,1645,880 \mathrm{~cm}^{-1} ;{ }^{1} \mathrm{H} \mathrm{NMR}\left(\mathrm{CDCl}_{3}\right.$, $300 \mathrm{MHz}$ ) $\delta 8.26\left(\mathrm{~s}, 1 \mathrm{H}, \mathrm{H}-2^{\prime}\right), 7.46$ (br s, $\left.1 \mathrm{H}, \mathrm{H}-5^{\prime}\right), 7.13$ (br s, $1 \mathrm{H}$ $\left.\mathrm{H}-4^{\prime}\right), 4.72\left(\mathrm{~d}, J=1.4 \mathrm{~Hz}, 1 \mathrm{H}, \mathrm{H}-29_{\mathrm{a}}\right), 4.67-4,63\left(\mathrm{~m}, 2 \mathrm{H}, \mathrm{H}-28_{\mathrm{a}}\right.$ and $\left.\mathrm{H}-29_{\mathrm{b}}\right), 4.21$ (d, $\left.J=10.7 \mathrm{~Hz}, 1 \mathrm{H}, \mathrm{H}-28_{\mathrm{b}}\right), 3.19$ (dd, $J=10.8 \mathrm{~Hz}$, $J=5.2 \mathrm{~Hz}, 1 \mathrm{H}, \mathrm{H}-3 \alpha), 2.47(\mathrm{dt}, J=10.7 \mathrm{~Hz}, J=5.6 \mathrm{~Hz}, 1 \mathrm{H}, \mathrm{H}-19)$, 1.70 (s, 3H, H-30), 1.06 (s, 3H), 1.01 (s, 3H), 0.97 (s, 3H), 0.83 (s, 3H), $0.76(\mathrm{~s}, 3 \mathrm{H}) ;{ }^{13} \mathrm{C} \mathrm{NMR}\left(\mathrm{CDCl}_{3}, 75 \mathrm{MHz}\right) \delta 149.5$ (C20), 148.7 (OCO), 136.8 (C2'), 129.6 (C4'), 117.2 (C5'), 110.3 (C29), 78.9 (C3), 67.5 (C28); EI-MS $m / z$ (\% rel. intensity): 536 (12) $\mathrm{M}^{+}, 207$ (36), 189 (39), 187 (54), 119 (44), 107 (34), 105 (34), 91 (46), 79 (38), 69 (100) and compound 15 (56 mg, 20\%): mp (acetone/n-hexane) 161-163 ${ }^{\circ} \mathrm{C}$; IR (film) $v_{\max } 3070,1757,1642,880 \mathrm{~cm}^{-1}$; ${ }^{1} \mathrm{H}$ NMR 
$\left(\mathrm{CDCl}_{3}, 300 \mathrm{MHz}\right): \delta 8.23$ and 8.22 (both s, each $\left.1 \mathrm{H}, \mathrm{H}-2^{\prime}, \mathrm{H}-2^{\prime \prime}\right)$, 7.45 (s, 2H, H-5' and $\left.\mathrm{H}^{\prime} 5^{\prime \prime}\right), 7.12\left(\mathrm{~s}, 2 \mathrm{H}, \mathrm{H}-4^{\prime}\right.$ and $\left.\mathrm{H}-4^{\prime \prime}\right), 4.73-4.64$ (m, $4 \mathrm{H}, \mathrm{H}-3 \alpha, \mathrm{H}-28_{\mathrm{a}}, \mathrm{H}-29_{\mathrm{a}}$ and $\left.\mathrm{H}-29_{\mathrm{b}}\right), 4.20$ (d, $J=10.7 \mathrm{~Hz}, 1 \mathrm{H}$, $\mathrm{H}-28_{\mathrm{b}}$ ), 2.48 (m, 1H, H-19), 1.71 (s, 3H, H-30), 1.08 (s, 3H), 1.02 $(\mathrm{s}, 3 \mathrm{H}), 0.96(\mathrm{~s}, 6 \mathrm{H}), 0.91(\mathrm{~s}, 3 \mathrm{H}) ;{ }^{13} \mathrm{C} \mathrm{NMR}\left(\mathrm{CDCl}_{3}, 75 \mathrm{MHz}\right): \delta$ 149.4 (C20), 148.9 (OCO), 148.2 (OCO), 136.8 and $136.7\left(\mathrm{C} 2^{\prime}\right.$, $\left.\mathrm{C} 2^{\prime \prime}\right), 130.0$ and $129.5\left(\mathrm{C}^{\prime}, \mathrm{C} 4^{\prime \prime}\right), 117.2$ and $117.1\left(\mathrm{C}^{\prime}, \mathrm{C}^{\prime \prime}\right), 110.3$ (C29), 86.8 (C3), 67.3 (C28); EI-MS $m / z$ (\% rel. intensity): 630 (2) $\mathrm{M}^{+}, 189$ (67), 187 (73), 119 (72), 105 (80), 95 (65), 93 (56), 91 (84), 79 (60), 69 (100).

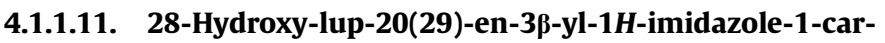
boxylate (16). A solution of compound 1 (200 mg, $0.45 \mathrm{mmol}$ ) and CDI (365 mg, $2.25 \mathrm{mmol})$ in anhydrous THF ( $8 \mathrm{ml}$ ) was refluxed for $9 \mathrm{~h}$ to afford compound 15. Silica gel $(200 \mathrm{mg})$ was added and this mixture was stirred at room temperature for $18 \mathrm{~h}$. The solid was filtered off and the filtrate was poured onto water $(30 \mathrm{ml})$ and extracted with diethyl ether $(3 \times 30 \mathrm{ml})$. The organic phase was then washed with water $(30 \mathrm{ml})$, and brine $(30 \mathrm{ml})$, dried with $\mathrm{Na}_{2} \mathrm{SO}_{4}$, filtered and evaporated to dryness. The crude product was purified by FCC eluting with petroleum ether $40-60{ }^{\circ} \mathrm{C} /$ ethyl acetate $(3: 2)$ to yield compound 16 (166 mg, 68\%): $\mathrm{mp}$ (acetone $/ n$-hexane) $198-199{ }^{\circ} \mathrm{C}$; IR (film) $v_{\max }$ 3327, 3070, 1758, 1645, $882 \mathrm{~cm}^{-1} ;{ }^{1} \mathrm{H}$ NMR $\left(\mathrm{CDCl}_{3}, 300 \mathrm{MHz}\right) \delta$ 8.29 (s, $\left.1 \mathrm{H}, \mathrm{H}-2^{\prime}\right), 7.47$ (s, $\left.1 \mathrm{H}, \mathrm{H}-5^{\prime}\right), 7.15$ (s, 1H, H-4'), 4.73-4.69 $\left(\mathrm{m}, 2 \mathrm{H}, \mathrm{H}-3 \alpha\right.$ and $\left.\mathrm{H}-29_{\mathrm{a}}\right), 4.59\left(\mathrm{~m}, 1 \mathrm{H}, \mathrm{H}-29_{\mathrm{b}}\right), 3.80(\mathrm{~d}, J=10.7 \mathrm{~Hz}$, $1 \mathrm{H}, \mathrm{H}-28_{\mathrm{a}}$ ), 3.34 (d, $J=10.7 \mathrm{~Hz}, 1 \mathrm{H}, \mathrm{H}-28_{\mathrm{b}}$ ), 2.40 (dt, $J=10.7 \mathrm{~Hz}$, $J=5.7 \mathrm{~Hz}, 1 \mathrm{H}, \mathrm{H}-19), 1.69(\mathrm{~s}, 3 \mathrm{H}, \mathrm{H}-30), 1.04(\mathrm{~s}, 3 \mathrm{H}), 0.99(\mathrm{~s}, 3 \mathrm{H})$, $0.96(\mathrm{~s}, 3 \mathrm{H}), 0.95(\mathrm{~s}, 3 \mathrm{H}), 0.89(\mathrm{~s}, 3 \mathrm{H}) ;{ }^{13} \mathrm{C} \mathrm{NMR}\left(\mathrm{CDCl}_{3}, 75 \mathrm{MHz}\right) \delta$ 150.4 (C20), 147.9 (OCO), $136.6\left(\mathrm{C}^{\prime}\right), 128.9\left(\mathrm{C}^{\prime}\right), 117.4\left(\mathrm{C5}^{\prime}\right)$, 109.7 (C29), 87.1 (C3), 60.4 (C28); EI-MS $m / z$ (\% rel. intensity): 536 (6) M+, 203 (37), 189 (35), 119 (41), 105 (37), 95 (35), 91 (30), 81 (29), 79 (32), 69 (100).

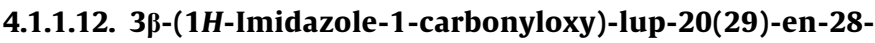
oic acid (17) and 28-(1H-imidazol-1-yl)-28-oxo-lup-20(29)-en3ß-yl-1H-imidazole-1-carboxylate (18). The method followed that described for compound 14 but using compound 2 (297 mg, $0.65 \mathrm{mmol}$ ) and CDI (527 mg, $3.25 \mathrm{mmol}$ ) in anhydrous THF $(12 \mathrm{ml})$ at reflux for $7 \mathrm{~h}$. The resulting yellowish solid was purified by FCC using petroleum ether $40-60{ }^{\circ} \mathrm{C} /$ ethyl acetate $(2: 3)$ to afford compound 17 (249 mg, 70\%): mp (acetone/n-hexane) 228$230^{\circ} \mathrm{C}$; IR (film) $v_{\max } 3070,1762,1699,1642 \mathrm{~cm}^{-1} ;{ }^{1} \mathrm{H}$ NMR $\left(\mathrm{CDCl}_{3}, 300 \mathrm{MHz}\right) \delta 8.21\left(\mathrm{~s}, 1 \mathrm{H}, \mathrm{H}-2^{\prime}\right), 7.43\left(\mathrm{~s}, 1 \mathrm{H}, \mathrm{H}-5^{\prime}\right), 7.12(\mathrm{~s}$, $1 \mathrm{H}, \mathrm{H}-4^{\prime}$ ), 4.75 (br s, $1 \mathrm{H}, \mathrm{H}-29_{\mathrm{a}}$ ), 4.69 (dd, $J=10.1 \mathrm{~Hz}, J=6.2 \mathrm{~Hz}$, $1 \mathrm{H}, \mathrm{H}-3 \alpha$ ), 4.62 (br s, $1 \mathrm{H}, \mathrm{H}-29_{\mathrm{b}}$ ), 3.04 (dt, $J=10.7 \mathrm{~Hz}, J=4.1 \mathrm{~Hz}$, $1 \mathrm{H}, \mathrm{H}-19), 1.70$ (s, 3H, H-30), 0.99 (s, 3H), 0.96-0.95 (m, 9H),

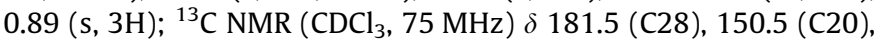
148.3 (OCO), $136.9\left(\mathrm{C}^{\prime}\right), 129.8\left(\mathrm{C}^{\prime}\right), 117.2\left(\mathrm{C}^{\prime}\right), 109.7$ (C29), 86.6 (C3); EI-MS $m / z$ (\% rel. intensity): 550 (4) $\mathrm{M}^{+}, 203$ (41), 189 (50), 187 (40), 175 (42), 159 (37), 119 (47), 91 (41), 79 (36), 69 (100) and compound 18 ( $88 \mathrm{mg}, 23 \%): \mathrm{mp}$ (acetone/n-hexane) 150-151 ${ }^{\circ} \mathrm{C}$; IR (film) $v_{\max } 3073,1757,1722,1642 \mathrm{~cm}^{-1} ;{ }^{1} \mathrm{H}$ NMR $\left(\mathrm{CDCl}_{3}, 400 \mathrm{MHz}\right) \delta 8.28\left(\mathrm{~s}, 1 \mathrm{H}, \mathrm{H}^{\prime}\right), 8.13\left(\mathrm{~s}, 1 \mathrm{H}, \mathrm{H} 2^{\prime \prime}\right), 7.53(\mathrm{~s}$, $\left.1 \mathrm{H}, \mathrm{H}-5^{\prime}\right), 7.41$ (s, 1H, H-5'), 7.07 (s, 1H, H-4') 7.05 (s, 1H, H-4'), 4.78 (br s, 1H, H-29a), 4.69-4.66 (m, 2H, H-3 $\alpha, \mathrm{H}-29_{\mathrm{b}}$ ), 2.97 (dt, $J=10.9 \mathrm{~Hz}, J=4.5 \mathrm{~Hz}, 1 \mathrm{H}, \mathrm{H}-19), 1.72(\mathrm{~s}, 3 \mathrm{H}, \mathrm{H}-30), 1.01$ (s, 3H), $0.95(\mathrm{~s}, 9 \mathrm{H}), 0.91(\mathrm{~s}, 3 \mathrm{H}) ;{ }^{13} \mathrm{C} \mathrm{NMR}\left(\mathrm{CDCl}_{3}, 100 \mathrm{MHz}\right) \delta 172.9$ (C28) 149.7 (C20), 148.5 (OCO), 137.3 (C2'), 137.0 (C2'), 130.5 (C4"), 129.6 (C4'), $117.4\left(\mathrm{C5}^{\prime}\right), 117.0\left(\mathrm{C5}^{\prime \prime}\right), 110.2$ (C29), 86.3 (C3); EI-MS m/z (\% rel. intensity): 600 (4) $\mathrm{M}^{+}, 393$ (33), 203 (22), 189 (31), 107 (27), 105 (27), 95 (38), 91 (28), 81 (24), 69 (100).

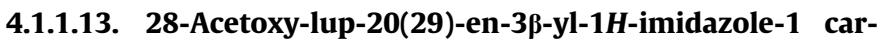
boxylate (19). The method followed that described for compound 14 but using compound 3 (242 mg, $0.5 \mathrm{mmol}$ ) and CDI (162 mg,
$1 \mathrm{mmol})$ in anhydrous THF $(10 \mathrm{ml})$ at reflux for $7 \mathrm{~h}$. The resulting white solid was purified by FCC using petroleum ether $40-60^{\circ} \mathrm{C} /$ ethyl acetate (4:1) to afford compound 19 (235 mg, 81\%): $\mathrm{mp}$ (acetone $/ n$-hexane) $194-195^{\circ} \mathrm{C}$; IR (film) $v_{\max } 3070,1756,1733,1642$, 1239, $882 \mathrm{~cm}^{-1}$; ${ }^{1} \mathrm{H}$ NMR $\left(\mathrm{CDCl}_{3}, 400 \mathrm{MHz}\right) \delta 8.12\left(\mathrm{~s}, 1 \mathrm{H}, \mathrm{H}-2^{\prime}\right), 7.41$ (s, $\left.1 \mathrm{H}, \mathrm{H}-5^{\prime}\right), 7.07\left(\mathrm{~s}, 1 \mathrm{H}, \mathrm{H}-4^{\prime}\right), 4.70-4.66\left(\mathrm{~m}, 2 \mathrm{H}, \mathrm{H}-3 \alpha\right.$ and $\left.\mathrm{H}-29_{\mathrm{a}}\right)$ $4.60\left(\mathrm{~s}, 1 \mathrm{H}, \mathrm{H}-29_{\mathrm{b}}\right), 4.26\left(\mathrm{~d}, J=11.0 \mathrm{~Hz}, 1 \mathrm{H}, \mathrm{H}-28_{\mathrm{a}}\right), 3.85$ (d, $\left.J=11.0 \mathrm{~Hz}, 1 \mathrm{H}, \mathrm{H}-28_{\mathrm{b}}\right), 2.45(\mathrm{dt}, J=10.8 \mathrm{~Hz}, J=5.9 \mathrm{~Hz}, 1 \mathrm{H}, \mathrm{H}-19)$, 2.07 (s, 3H, $\left.\mathrm{OCOCH}_{3}\right), 1.69$ (s, 3H, H-30), 1.05 (s, 3H), 0.99 (s, 3H), $0.95(\mathrm{~s}, 6 \mathrm{H}), 0.89(\mathrm{~s}, 3 \mathrm{H}) ;{ }^{13} \mathrm{C}$ NMR $\left(\mathrm{CDCl}_{3}, 100 \mathrm{MHz}\right) \delta 171.6$ $\left(\mathrm{OCOCH}_{3}\right), 150.0(\mathrm{C} 20), 148.5(\mathrm{OCO}), 137.0\left(\mathrm{C}^{\prime}\right), 130.5\left(\mathrm{C}^{\prime}\right)$, 117.0 (C5'), 109.9 (C29), 86.3 (C3), 62.8 (C28); El-MS m/z (\% rel. intensity): 578 (5), $\mathrm{M}^{+}, 189$ (64), 187 (56), 145 (44), 133 (43), 119 (51), 105 (66), 95 (50), 91 (71), 69 (100).

4.1.1.14. 3ß-Acetoxy-lup-20(29)-en-28-yl-1H-imidazole-1-carboxylate (20). The method followed that described for compound 14 but using compound 4 (242 mg, $0.5 \mathrm{mmol}$ ) and CDI (162 mg, $1 \mathrm{mmol})$ in anhydrous THF $(10 \mathrm{ml})$ at reflux for $5 \mathrm{~h}$. The resulting white solid was purified by FCC using petroleum ether $40-60{ }^{\circ} \mathrm{C} /$ ethyl acetate (4:1) to afford compound 20 (247 mg, 85\%): $\mathrm{mp}$ (acetone $/ n$-hexane) $101-103^{\circ} \mathrm{C}$; IR (film) $v_{\max } 3073,1760,1730,1642$, $1240,882 \mathrm{~cm}^{-1}$; ${ }^{1} \mathrm{H}$ NMR $\left(\mathrm{CDCl}_{3}, 300 \mathrm{MHz}\right) \delta 8.22\left(\mathrm{~s}, 1 \mathrm{H}, \mathrm{H}-2^{\prime}\right), 7.45$ (s, 1H, H-5'), 7.12 (s, 1H, H-4'), 4.72 (br s, $1 \mathrm{H}, \mathrm{H}-29_{\mathrm{a}}$ ), 4.67-4.63 (m, $2 \mathrm{H}, \mathrm{H}-28_{\mathrm{a}}$ and $\left.\mathrm{H}-29_{\mathrm{b}}\right), 4.47$ (dd, $J=10.2 \mathrm{~Hz}, J=5.8 \mathrm{~Hz}, 1 \mathrm{H}, \mathrm{H}-3 \alpha$ ), 4.20 (d, $J=10.6 \mathrm{~Hz}, 1 \mathrm{H}, \mathrm{H}-28_{\mathrm{b}}$ ), 2.48 (m, 1H, H-19), 2.05 (s, 3H, $\left.\mathrm{OCOCH}_{3}\right), 1.71(\mathrm{~s}, 3 \mathrm{H}, \mathrm{H}-30), 1.06(\mathrm{~s}, 3 \mathrm{H}), 1.00(\mathrm{~s}, 3 \mathrm{H}), 0.86(\mathrm{~s}$, $3 \mathrm{H}), 0.85(\mathrm{~s}, 3 \mathrm{H}), 0.84(\mathrm{~s}, 3 \mathrm{H}) ;{ }^{13} \mathrm{C} \mathrm{NMR}\left(\mathrm{CDCl}_{3}, 75 \mathrm{MHz}\right) \delta 170.9$ $\left(\mathrm{OCOCH}_{3}\right), 149.5(\mathrm{C} 20), 148.8(\mathrm{OCO}), 136.8\left(\mathrm{C}^{\prime}\right), 129.9\left(\mathrm{C}^{\prime}\right)$, 117.2 (C5'), 110.3 (C29), 80.8 (C3), 67.4 (C28); EI-MS m/z (\% rel. intensity): 578 (19) $\mathrm{M}^{+}, 189$ (24), 187 (26), 133 (20), 119 (35), 105 (36), 93 (19), 91 (42), 79 (26), 69 (100).

4.1.1.15. Methyl 3ß-(1H-imidazole-1-carbonyloxy)-lup-20(29)en-28-oate (21). The method followed that described for compound 14 but using compound $5(100 \mathrm{mg}, 0.2 \mathrm{mmol})$ and CDI ( $65 \mathrm{mg}, 0.4 \mathrm{mmol}$ ) in anhydrous THF $(4 \mathrm{ml})$, at reflux for $6 \mathrm{~h}$. The crude product was purified by FCC eluting with petroleum ether 40-60 ${ }^{\circ}$ C/ethyl acetate (3:2) to yield compound 21 (105 mg, 88\%): $\mathrm{mp}$ (acetone $/ n$-hexane) $220-224^{\circ} \mathrm{C}$; IR (film) $v_{\max } 3070,1758$, $1725,1642,1240 \mathrm{~cm}^{-1} ;{ }^{1} \mathrm{H}$ NMR $\left(\mathrm{CDCl}_{3}, 300 \mathrm{MHz}\right) \delta 8.24(\mathrm{~s}, 1 \mathrm{H}$, $\mathrm{H} 2^{\prime}$ ), 7.45 (s, $\left.1 \mathrm{H}, \mathrm{H}-5^{\prime}\right), 7.13$ (s, 1H, H-4'), 4.74-4.67 (m, 2H, H-3 $\alpha$, $\mathrm{H}-29_{\mathrm{a}}$ ), 4.61 (br s, 1H, H-29b), 3.67 (s, 3H, $\mathrm{COOCH}_{3}$ ), 3.00 (dt, $J=10.3 \mathrm{~Hz}, J=3.7 \mathrm{~Hz}, 1 \mathrm{H}, \mathrm{H}-19$ ), 1.69 (s, 3H, H-30), 0.97 (s, 3H), $0.95(\mathrm{~s}, 6 \mathrm{H}), 0.93(\mathrm{~s}, 3 \mathrm{H}), 0.89(\mathrm{~s}, 3 \mathrm{H}) ;{ }^{13} \mathrm{C} \mathrm{NMR}\left(\mathrm{CDCl}_{3}, 75 \mathrm{MHz}\right) \delta$ 176.6 (C28), 150.5 (C20), 148.1 (OCO), $136.6\left(\mathrm{C}^{\prime}\right), 129.3\left(\mathrm{C}^{\prime}\right)$, 117.2 (C5'), 109.6 (C29), 86.9 (C3); EI-MS m/z (\% rel. intensity): 564 (4) M+ 203 (35), 190 (28), 189 (71), 187 (38), 175 (35), 119 (43), 105 (33), 91 (37), 79 (33), 69 (100).

4.1.1.16. 33-Hydroxy-30-methoxylup-20(29)-en-28-yl-1H-imidazole-1-carboxylate (22) and 30-methoxylup-20(29)-en-3及,28di-yl-(1H-imidazole-1-carboxylate) (23). The method followed that described for compound 14 but using compound 7 (213 mg, $0.45 \mathrm{mmol})$ and CDI (219 $\mathrm{mg}, 1.35 \mathrm{mmol})$ in anhydrous THF $(8 \mathrm{ml})$, at reflux for $8 \mathrm{~h}$. The resulting white solid was purified by FCC eluting with petroleum ether $40-60^{\circ} \mathrm{C} /$ ethyl acetate $(1: 1)$ to afford compound 22 (174 $\mathrm{mg}, 68 \%)$ : $\mathrm{mp}$ (acetone $/ n$-hexane) $136-138^{\circ} \mathrm{C}$; IR (film) $v_{\max } 3406,3078,1760,1645,1239 \mathrm{~cm}^{-1} ;{ }^{1} \mathrm{H} \mathrm{NMR}\left(\mathrm{CDCl}_{3}\right.$, $300 \mathrm{MHz}) \delta 8.23\left(\mathrm{~s}, 1 \mathrm{H}, \mathrm{H}-2^{\prime}\right), 7.47\left(\mathrm{~s}, 1 \mathrm{H}, \mathrm{H}-5^{\prime}\right), 7.13\left(\mathrm{~s}, 1 \mathrm{H}, \mathrm{H}-4^{\prime}\right)$, 4.98 (s, 1H, H-29a), 4.95 (s, 1H, H-29 b), 4.65 (d, J=10.8 Hz, 1H, H$28_{\mathrm{a}}$ ), 4.21 (d, J=10.8 Hz, 1H, H-28b), 3.89 (s, 2H, H-30), 3.38 (s, 3H, $\left.\mathrm{OCH}_{3}\right), 3.20(\mathrm{dd}, J=10.8 \mathrm{~Hz}, J=5.1 \mathrm{~Hz}, 1 \mathrm{H}, \mathrm{H}-3 \alpha), 2.39$ (dt, $J=11.0 \mathrm{~Hz}, J=5.3 \mathrm{~Hz}, 1 \mathrm{H}, \mathrm{H}-19), 1.07$ (s, 3H), 1.02 (s, 3H), 0.98 (s, $3 \mathrm{H}), 0.84(\mathrm{~s}, 3 \mathrm{H}), 0.78(\mathrm{~s}, 3 \mathrm{H}) ;{ }^{13} \mathrm{C} \mathrm{NMR}\left(\mathrm{CDCl}_{3}, 75 \mathrm{MHz}\right) \delta 150.3$ (C20), 148.8 (OCO), 136.8 (C2'), 129.9 (C4'), 117.2 (C5'), 109.7 
(C29), 78.8 (C3), 74.9 (C30), 67.2 (C28), $58.3\left(\mathrm{OCH}_{3}\right)$; EI-MS $m / z$ (\% rel. intensity): 566 (7) $\mathrm{M}^{+}, 187$ (30), 119 (34), 105 (32), 93 (32), 91 (46), 81 (33), 79 (39), 69 (100), 67 (29) and compound 23 (83 mg, 28\%): $\mathrm{mp}$ (acetone $/ n$-hexane) $174-176^{\circ} \mathrm{C}$; IR (film) $v_{\max } 3078,1757$, $1645,1239 \mathrm{~cm}^{-1} ;{ }^{1} \mathrm{H}$ NMR $\left(\mathrm{CDCl}_{3}, 400 \mathrm{MHz}\right) \delta 8.15\left(\mathrm{~s}, 1 \mathrm{H}, \mathrm{H}-2^{\prime}\right)$, $8.13\left(\mathrm{~s}, 1 \mathrm{H}, \mathrm{H}-2^{\prime \prime}\right), 7.43\left(\mathrm{~s}, 1 \mathrm{H}, \mathrm{H}-5^{\prime}\right), 7.41\left(\mathrm{~s}, 1 \mathrm{H}, \mathrm{H}-5^{\prime \prime}\right), 7.08(\mathrm{~s}, 1 \mathrm{H}$, H-4') 7.07 (s, 1H, H-4'), 4.98 (s, 1H, H-29a), 4.95 (s, 1H, H-29b), 4.70-4.62 (m, 2H, H-3 $\alpha, \mathrm{H}-28_{\mathrm{a}}$ ), 4.18 (d, $J=10.7 \mathrm{~Hz}, 1 \mathrm{H}, \mathrm{H}-28_{\mathrm{b}}$ ), $3.89(\mathrm{~s}, 2 \mathrm{H}, \mathrm{H}-30), 3.37\left(\mathrm{~s}, 3 \mathrm{H}, \mathrm{OCH}_{3}\right), 2.40(\mathrm{dt}, J=11.0 \mathrm{~Hz}$, $J=5.3 \mathrm{~Hz}, 1 \mathrm{H}, \mathrm{H}-19), 1.09$ (s, 3H), 1.03 (s, 3H), 0.96 (s, 6H), 0.91 (s, $3 \mathrm{H}) ;{ }^{13} \mathrm{C} \mathrm{NMR}\left(\mathrm{CDCl}_{3}, 100 \mathrm{MHz}\right) \delta 150.4$ (C20), 149.1 (OCO), 148.5 (OCO), 137.0 (C2', C2' $), 130.7$ and 130.6 (C4', C4" $), 117.0\left(\mathrm{C}^{\prime \prime}, \mathrm{C}^{\prime \prime}\right)$, 109.9 (C29), 86.2 (C3), 75.1 (C30), 66.9 (C28), $58.4\left(\mathrm{OCH}_{3}\right)$; EI-MS $\mathrm{m} / \mathrm{z}$ (\% rel. intensity): 660 (11) $\mathrm{M}^{+}, 199$ (23), 189 (25), 187 (30), 145 (28), 143 (20), 119 (22), 105 (21), 91 (34), 69 (100).

\subsubsection{3 3 -Hydroxy-(20R)-lupan-29-oxo-28-yl-1H-imidazole-} 1-carboxylate (24) and (20R)-lupan-29-oxo-3ß,28-di-yl-(1Himidazole-1-carboxylate) (25). The method followed that described for compound 14 but using compound 9 (298 mg, $0.65 \mathrm{mmol}$ ) and CDI (316 mg, $1.95 \mathrm{mmol}$ ) in anhydrous THF $(12 \mathrm{ml})$, at reflux for $7 \mathrm{~h}$. The resulting white solid was purified by FCC eluting with petroleum ether $40-60{ }^{\circ} \mathrm{C} /$ ethyl acetate $(2: 3)$ to afford compound 24 (239 $\mathrm{mg}, 67 \%): \mathrm{mp}$ (acetone/n-hexane) 175-177 ${ }^{\circ} \mathrm{C}$; IR (film) $v_{\max } 3414,1762,1722,1239 \mathrm{~cm}^{-1} ;{ }^{1} \mathrm{H}$ NMR $\left(\mathrm{CDCl}_{3}, 400 \mathrm{MHz}\right) \delta 9.85(\mathrm{~d}, J=1.9 \mathrm{~Hz}, 1 \mathrm{H}, \mathrm{H}-29), 8.15$ (br s, $1 \mathrm{H}$, $\mathrm{H}-2^{\prime}$ ), 7.42 (br s, $\left.1 \mathrm{H}, \mathrm{H}-5^{\prime}\right), 7.09$ (br s, 1H, H-4') 4.60 (d, $J=10.9 \mathrm{~Hz}, 1 \mathrm{H}, \mathrm{H}-28_{\mathrm{a}}$ ), 4.13 (d, $J=10.9 \mathrm{~Hz}, 1 \mathrm{H}, \mathrm{H}-28_{\mathrm{b}}$ ), 3.21 (dd, $J=10.8 \mathrm{~Hz}, J=5.1 \mathrm{~Hz}, 1 \mathrm{H}, \mathrm{H}-3 \alpha), 2.64(\mathrm{~m}, 1 \mathrm{H}, \mathrm{H}-20), 1.15$ (d, $J=7.0 \mathrm{~Hz}, 3 \mathrm{H}, \mathrm{H}-30), 1.07$ (s, 3H), 0.98 (s, 6H), 0.85 (s, 3H), 0.77 (s, 3H); ${ }^{13} \mathrm{C}$ NMR $\left(\mathrm{CDCl}_{3}, 100 \mathrm{MHz}\right) \delta 206.3$ (C29), 149.1 (OCO), 137.0 (C2'), 130.6 (C4'), 117.1 (C5'), 78.8 (C3), 66.4 (C28), 48.8 (C20), 14.4 (C30); EI-MS m/z (\% rel. intensity): 552 (18) $\mathrm{M}^{+}, 207$ (46), 189 (58), 187 (47), 145 (49), 119 (45), 105 (51), 91 (58), 79 (48), 69 (100) and compound 25 (128 mg, 30\%): mp (acetone $/ n$ hexane) $145-146{ }^{\circ} \mathrm{C}$; IR (film) $v_{\max } 1758,1716,1239 \mathrm{~cm}^{-1} ;{ }^{1} \mathrm{H}$ NMR $\left(\mathrm{CDCl}_{3}, 300 \mathrm{MHz}\right) \delta 9.85$ (d, J=1.9 Hz, 1H, H-29), 8.15 (br s, $2 \mathrm{H}, \mathrm{H}-2^{\prime}, \mathrm{H}-2^{\prime \prime}$ ), 7.43 (br s, 2H, H-5', H-5'), 7.09 (br s, 2H, H-4', H$\left.4^{\prime \prime}\right), 4.69(\mathrm{dd}, J=10.9 \mathrm{~Hz}, J=5.4 \mathrm{~Hz}, 1 \mathrm{H}, \mathrm{H}-3 \alpha), 4.61(\mathrm{~d}, J=10.9 \mathrm{~Hz}$, $\left.1 \mathrm{H}, \mathrm{H}-28_{\mathrm{a}}\right), 4.13$ (d, J=10.9 Hz, 1H, H-28 $), 2.64(\mathrm{~m}, 1 \mathrm{H}, \mathrm{H}-20)$, 1.16 (d, $J=7.0 \mathrm{~Hz}, 3 \mathrm{H}, \mathrm{H}-30), 1.09$ (s, 3H), 0.99 (s, 3H), 0.97 (s, $6 \mathrm{H}), 0.92(\mathrm{~s}, 3 \mathrm{H}) ;{ }^{13} \mathrm{C} \mathrm{NMR}\left(\mathrm{CDCl}_{3}, 75 \mathrm{MHz}\right) \delta 206.1$ (C29), 148.9 (OCO), 148.4 (OCO) 136.9 (C2', C2" $), 130.6\left(\mathrm{C}^{\prime}, \mathrm{C}^{\prime \prime}\right), 117.0$ (C5', $\mathrm{C}^{\prime \prime}$ ), 86.2 (C3), 66.3 (C28); EI-MS $m / z$ (\% rel. intensity): 646 (6) $\mathrm{M}^{+}, 187$ (23), 159 (23), 119 (23), 105 (29), 93 (20), 91 (34), 81 (19), 79 (22), 69 (100).

\subsubsection{28-(1H-Imidazol-1-yl)-lup-20(29)-en-3,28-dione (26).}

The method followed that described for compound 14 but using compound 11 (205 mg, $0.45 \mathrm{mmol}$ ) and CDI (219 mg, $1.35 \mathrm{mmol})$ in anhydrous THF $(8 \mathrm{ml})$, at reflux for $9 \mathrm{~h}$. The crude product was purified by FCC eluting with petroleum ether $40-60{ }^{\circ} \mathrm{C} /$ ethyl acetate (3:2) to yield compound 26 (203 $\mathrm{mg}, 89 \%)$ : mp (benzene) 189-190 ${ }^{\circ} \mathrm{C}$; IR (film) $v_{\max } 3073,1721,1703,1642 \mathrm{~cm}^{-1} ;{ }^{1} \mathrm{H}$ NMR $\left(\mathrm{CDCl}_{3}, 400 \mathrm{MHz}\right) \delta 8.28\left(\mathrm{~s}, 1 \mathrm{H}, \mathrm{H}-2^{\prime}\right), 7.54\left(\mathrm{~s}, 1 \mathrm{H}, \mathrm{H}-5^{\prime}\right), 7.05(\mathrm{~s}$, $\left.1 \mathrm{H}, \mathrm{H}-4^{\prime}\right), 4.78\left(\mathrm{~s}, 1 \mathrm{H}, \mathrm{H}-29_{\mathrm{a}}\right), 4.65\left(\mathrm{~s}, 1 \mathrm{H}, \mathrm{H}-29_{\mathrm{b}}\right), 2.97$ (dt, $J=10.7 \mathrm{~Hz}, J=4.2 \mathrm{~Hz}, 1 \mathrm{H}, \mathrm{H}-19), 1.71$ (s, 3H, H-30), 1.06 (s, 3H), 1.01 (br s, 6H), $0.96(\mathrm{~s}, 3 \mathrm{H}), 0.94(\mathrm{~s}, 3 \mathrm{H}) ;{ }^{13} \mathrm{C} \mathrm{NMR}\left(\mathrm{CDCl}_{3}\right.$, $100 \mathrm{MHz}) \delta 217.9$ (C3), 172.9 (C28), 149.7 (C20), 137.3 (C2'), 129.6 (C4'), $117.4\left(\mathrm{C}^{\prime}\right), 110.2$ (C29); EI-MS $m / z$ (\% rel. intensity): 504 (4) M+ 410 (30), 409 (100), 245 (46), 203 (49), 189 (58), 147 (25), 107 (31), 105 (27), 91 (24).

4.1.1.19. 28-(1H-Imidazol-1-yl)-lup-1,20(29)-dien-3,28-dione (27). The method followed that described for compound 14 but using compound 12 (204 mg, $0.45 \mathrm{mmol}$ ) and CDI (219 mg,
$1.35 \mathrm{mmol})$ in anhydrous THF $(8 \mathrm{ml})$, at reflux for $9 \mathrm{~h}$. The crude product was purified by FCC eluting with petroleum ether $40-$ $60{ }^{\circ} \mathrm{C} /$ ethyl acetate (3:2) to yield compound 27 (186 mg, 82\%): $\mathrm{mp}$ (acetone $/ n$-hexane) $95-96^{\circ} \mathrm{C}$; IR (film) $v_{\max } 3070,1762$, $1720,1668,1645 \mathrm{~cm}^{-1} ;{ }^{1} \mathrm{H}$ NMR $\left(\mathrm{CDCl}_{3}, 400 \mathrm{MHz}\right) \delta 8.29(\mathrm{~s}, 1 \mathrm{H}$, $\left.\mathrm{H}-2^{\prime}\right), 7.54\left(\mathrm{~s}, 1 \mathrm{H}, \mathrm{H}-5^{\prime}\right), 7.12(\mathrm{~d}, J=10.1 \mathrm{~Hz}, 1 \mathrm{H}, \mathrm{H}-1), 7.05$ (s, $1 \mathrm{H}$, $\mathrm{H}-4^{\prime}$ ), 5.80 (d, J=10.1 Hz, 1H, H-2), 4.79 (s, 1H, H-29a), 4.67 (s, $1 \mathrm{H}, \mathrm{H}-29_{\mathrm{b}}$ ), 2.98 (dt, $\left.J=11.0 \mathrm{~Hz}, J=4.6 \mathrm{~Hz}, 1 \mathrm{H}, \mathrm{H}-19\right), 1.72(\mathrm{~s}, 3 \mathrm{H}$, $\mathrm{H}-30), 1.12$ (s, 3H), 1.07 (s, 6H), $1.01(\mathrm{~s}, 3 \mathrm{H}), 1.00(\mathrm{~s}, 3 \mathrm{H}) ;{ }^{13} \mathrm{C}$ $\mathrm{NMR}\left(\mathrm{CDCl}_{3}, 100 \mathrm{MHz}\right) \delta 205.4$ (C3), 172.6 (C28), 159.6 (C1), 149.5 (C20), 137.1 (C2'), 128.8 (C4'), 125.2 (C2), $117.5\left(\mathrm{C}^{\prime}\right)$, 110.3 (C29); EI-MS m/z (\% rel. intensity): 502 (4) $\mathrm{M}^{+}, 408$ (32), 407 (100), 243 (43), 205 (30), 203 (26), 189 (34), 135 (25), 105 (28), 91 (29).

4.1.1.20. 2-Hydroxy-28-(1H-imidazol-1-yl)-lup-1,20(29)-dien3,28-dione (28) and 28-(1H-imidazole-1-yl)-3,28-dioxo-lup1,20(29)-dien-2-yl-1H-imidazole-1-carboxylate (29). The method followed that described for compound 14 but using compound 13 (304 mg, $0.65 \mathrm{mmol}$ ) and CDI (524 mg, $3.25 \mathrm{mmol}$ ) in anhydrous THF $(12 \mathrm{ml})$, at reflux for $8 \mathrm{~h}$. The resulting white solid was purified by FCC eluting with petroleum ether $40-60{ }^{\circ} \mathrm{C} /$ ethyl acetate (1:4) to afford compound 28 (237 $\mathrm{mg}, 70 \%): \mathrm{mp}$ (acetone $/ n$ hexane) $145-148{ }^{\circ} \mathrm{C}$; IR (film) $v_{\max } 3448,3078,1762,1724,1667$, $1645 \mathrm{~cm}^{-1} ;{ }^{1} \mathrm{H}$ NMR $\left(\mathrm{CDCl}_{3}, 400 \mathrm{MHz}\right) \delta 8.43\left(\mathrm{~s}, 1 \mathrm{H}, \mathrm{H}-2^{\prime}\right), 7.56$ (s, 1H, H-5'), 7.09 (s, 1H, H-4'), 6.45 (s, 1H, H-1), 4.79 (s, 1H, H29a), 4.67 (s, 1H, H-29 b), 2.97 (dt, $J=10.6 \mathrm{~Hz}, J=4.0 \mathrm{~Hz}, 1 \mathrm{H}, \mathrm{H}-$ 19), 1.72 (s, 1H, H-30), 1.19 (s, 3H), 1.14 (s, 3H), 1.10 (s, 3H), 0.99 (br s, 6H); ${ }^{13} \mathrm{C}$ NMR $\left(\mathrm{CDCl}_{3}, 100 \mathrm{MHz}\right) \delta 201.1$ (C3), 172.9 (C28), 149.5 (C20), 143.9 (C2), 137.3 (C2'), 129.6 (C4'), 128.8 (C1), 117.4 (C5'), 110.4 (C29); EI-MS m/z (\% rel. intensity): 518 (22) $\mathrm{M}^{+}, 423$ (100), 215 (94), 213 (65), 189 (57), 119 (55), 105 (54), 91 (89), 79 (54), 69 (55) and compound 29 (109 mg, 27\%): mp (acetone/ n-hexane) $211-213^{\circ} \mathrm{C}$; IR (film) $v_{\max } 3070,1826,1757,1721$, $1642 \mathrm{~cm}^{-1} ;{ }^{1} \mathrm{H} \mathrm{NMR}\left(\mathrm{CDCl}_{3}, 300 \mathrm{MHz}\right) \delta 8.42$ and 8.27 (both s, each $\left.1 \mathrm{H}, \mathrm{H}-2^{\prime}, \mathrm{H}-2^{\prime \prime}\right), 7.79$ and 7.51 (both $\mathrm{s}$, each $\left.1 \mathrm{H}, \mathrm{H}-5^{\prime}, \mathrm{H}-5^{\prime \prime}\right), 7.21$ and 7.04 (both s, each $1 \mathrm{H}, \mathrm{H}-4^{\prime}, \mathrm{H}-4^{\prime \prime}$ ), 6.97 (s, $1 \mathrm{H}, \mathrm{H}-1$ ), 4.74 (br s, 1H, H-29a), 4.67 (br s, 1H, H-29b), 2.92 (dt, $J=10.9 \mathrm{~Hz}$, $J=4.6 \mathrm{~Hz}, 1 \mathrm{H}, \mathrm{H}-19), 1.73$ (s, 3H, H-30), 1.36 (s, 3H), 1.17 (s, 3H), $1.16(\mathrm{~s}, 3 \mathrm{H}), 1.00(\mathrm{~s}, 3 \mathrm{H}), 0.89(\mathrm{~s}, 3 \mathrm{H}) ;{ }^{13} \mathrm{C} \mathrm{NMR}\left(\mathrm{CDCl}_{3}, 75 \mathrm{MHz}\right) \delta$ 202.3 (C3), 172.8 (C28), 152.2 (C20), 149.1 (OCO), 146.5 (C2), $137.2\left(\mathrm{C2}^{\prime}\right.$ and $\left.\mathrm{C2}^{\prime \prime}\right), 132.6(\mathrm{C} 1), 129.6\left(\mathrm{C}^{\prime}\right.$ and $\left.\mathrm{C4}^{\prime \prime}\right), 117.3(\mathrm{C})^{\prime}$ and $\left.\mathrm{C}^{\prime \prime}\right), 110.6$ (C29); EI-MS $m / z$ (\% rel. intensity): 612 (9) $\mathrm{M}^{+}$, 518 (35), 517 (100), 449 (19), 405 (14), 295 (15), 189 (27), 105 (18), 91 (21), 69 (16).

\subsection{Antiproliferative activity}

\subsubsection{General}

All cell lines were purchased from the American Type Culture Collection (ATCC, Rockville, MD). RPMI 1640 medium, Dulbecco's Modified Eagle Medium (DMEM-D5796), Dulbecco's Phosphate Buffered Saline (DPBS), 3-(4,5-dimethylthiazol-2-yl)-2,5-diphenyltetrazolium bromide (MTT) powder and dimethylsulfoxide (DMSO) were obtained from Sigma-Aldrich Co. Penicillin/streptomycin $(\mathrm{P} / \mathrm{S})$ and L-glutamine were obtained from Gibco-BRL. Sodium pyruvate and trypsin/EDTA $(0.05 \% / 0.02 \%)$ were obtained from Biological Industries. Fetal Bovine Serum (FBS) were purchased from PAA Laboratories and XTT kit was obtained from Roche.

A-375, HT-29, HeLa, MIA PaCa-2 and SH-SY5Y cells were routinely maintained in DMEM supplemented with $10 \%$ heat-inactivated $\mathrm{FBS}$ and $1 \% \mathrm{P} / \mathrm{S}$ solution. HepG2 cells were maintained in DMEM supplemented with $10 \%$ heat-inactivated FBS, $1 \% \mathrm{P} / \mathrm{S}$ and $1 \mathrm{mM}$ of sodium pyruvate. Jurkat cells were grown in RPMI 1640 medium supplemented with $10 \%$ heat-inactivated FBS, $1 \% \mathrm{P} / \mathrm{S}$ 
and $2 \mathrm{mM}$ L-glutamine. MCF-7 were maintained in RPMI 1640 medium supplemented with $10 \%$ heat-inactivated $\mathrm{FBS}, 0.2 \% \mathrm{P} / \mathrm{S}$, $2 \mathrm{mM}$ L-glutamine, $1 \mathrm{mM}$ of sodium pyruvate and $0.1 \mathrm{mg} / \mathrm{ml}$ of insulin.

All cell cultures were incubated at $37{ }^{\circ} \mathrm{C}$ in $5 \% \mathrm{CO}_{2}$ saturated atmosphere and 99\% humidity.

\subsubsection{Viability assay}

The cell viability of HeLa and HepG2 cells in the presence of the synthesized compounds was determined by the MTT assay. Briefly, exponentially growing cells were plated in 96-well plates at a density of $1 \times 10^{3}$ and $8 \times 10^{3}$ cells/well respectively and incubated for $24 \mathrm{~h}$ before treatment. The growth medium was replaced with one containing either the test compounds dissolved in DMSO (final DMSO concentration $<0.1 \%$ ) at different concentrations or only DMSO, in triplicate wells, and cells were incubated for $72 \mathrm{~h}$. After incubation with the compounds, the medium was removed and MTT solution $(0.5 \mathrm{mg} / \mathrm{ml}, 100 \mu \mathrm{l})$ was added to each well and the plates were incubated again for $1 \mathrm{~h}$. MTT solution was removed and DMSO $(100 \mu \mathrm{l})$ was then added to dissolve the formazan crystals. The plates were immediately read at $550 \mathrm{~nm}$ on an ELISA plate reader (Tecan Sunrise MR20-301, TECAN, Austria).

For Jurkat cells, the cell viability was determined by XTT assay. Briefly, exponentially growing cells were plated in 96-well plates at a density of $5.5 \times 10^{3}$ cells/well, treated with different concentrations of compounds or vehicle (medium with DMSO) in triplicate and incubated for $72 \mathrm{~h}$. After incubation with the compounds the XTT labeling mixture $(100 \mu \mathrm{l})$ was added to each of the wells and after a $4 \mathrm{~h}$ incubation period the plates were read at $450 \mathrm{~nm}$ on an ELISA plate reader.

Concentrations that inhibit cell growth by $50 \%\left(\mathrm{IC}_{50}\right)$ compared to non-treated cells were determined by non-linear regression with Graphpad Prism software version 4.0 (GraphPad Software, Inc., San Diego, CA). All the $\mathrm{IC}_{50}$ results represent an average of a minimum of three experiments and were expressed as means \pm standard deviation (SD). Compound $\mathbf{2}$ was used as a positive control.

For the screening of antiproliferative activity, cell suspensions were prepared and diluted according to the particular cell type and the expected target cell density $\left(1 \times 10^{3}-30 \times 10^{3}\right.$ cells/well based on the cell growth characteristics). Cells were plated in 96well plates and cell viability was determined by the MTT assay (MCF-7, HepG2, A-375, HT-29, HeLa and MIA PaCa-2) or XTT assay (Jurkat and SH-SY5Y) after $72 \mathrm{~h}$ of incubation with the different derivatives at the concentration of $20 \mu \mathrm{M}$, in triplicate.

\section{Acknowledgements}

R.C.S. thanks Fundação para a Ciência e a Tecnologia for supporting this work (SFRH/BD/23770/2005). J.A.R.S. thanks Universidade de Coimbra for financial support. M.C. thanks Ministerio de Ciencia e Innovación (SAF2008-00164) and ISCIII-RTICC (RD06/0020/0046) from the Spanish government and the European Union FEDER funds from the Spanish government and European Union FEDER funds.

\section{Supplementary data}

Supplementary data associated with this article can be found, in the online version, at doi:10.1016/j.bmc.2009.07.050.

\section{References and notes}

1. Setzer, W. N.; Setzer, M. C. Mini-Rev. Med. Chem. 2003, 3, 540.

2. Kinghorn, A. D.; Su, B. N.; Jang, D. S.; Chang, L. C.; Lee, D.; Gu, J. Q.; CarcacheBlanco, E. J.; Powlus, A. D.; Lee, S. K.; Park, E. J.; Cuendet, M.; Gills, J. J.; Bhat, K.;
Park, H. S.; Mata-Greenwood, E.; Song, L. L.; Jong, M. H.; Pezzuto, J. M. Planta Med. 2004, 70, 691.

3. Krasutsky, P. A. Nat. Prod. Rep. 2006, 23, 919.

4. Kim, D. S. H. L.; Chen, Z.; Nguyen, T.; Pezzuto, J. M.; Qiu, S.; Lu, Z.-Z. Synth. Commun. 1997, 27, 1607.

5. Dzubak, P.; Hajduch, M.; Vydra, D.; Hustova, A.; Kvasnica, M.; Biedermann, D.; Markova, L.; Urban, M.; Sarek, J. Nat. Prod. Rep. 2006, 23, 294.

6. Tolstikova, T. G.; Sorokina, I. V.; Tolstikov, G. A.; Tolstikov, A. G.; Flekhter, O. B. Russ. J. Bioorg. Chem. 2006, 32, 37.

7. Pisha, E.; Chai, H.; Lee, I. S.; Chagwedera, T. E.; Farnsworth, N. R.; Cordell, G. A.; Beecher, C. W. W.; Fong, H. H. S.; Kinghorn, A. D.; Brown, D. M.; Wani, M. C.; Wall, M. E.; Hieken, T. J.; Dasgupta, T. K.; Pezzuto, J. M. Nat. Med. 1995, 1, 1046.

8. Schmidt, M. L.; Kuzmanoff, K. L.; Indeck, L. L.; Pezzuto, J. M. Eur. J. Cancer 1997, 33, 2007.

9. Fulda, S.; Jeremias, I.; Steiner, H. H.; Pietsch, T.; Debatin, K.-M. Int. J. Cancer 1999, 82, 435.

10. Thurnher, D.; Turhani, D.; Pelzmann, M.; Wannemacher, B.; Knerer, B.; Formanek, M.; Wacheck, V.; Selzer, E. Head Neck 2003, 25, 732.

11. Kessler, J. H.; Mullauer, F. B.; de Roo, G. M.; Medema, J. P. Cancer Lett. 2007, 251, 132.

12. Fulda, S.; Friesen, C.; Los, M.; Scaffidi, C.; Mier, W.; Benedict, M.; Nunez, G.; Krammer, P. H.; Peter, M. E.; Debatin, K. M. Cancer Res. 1997, 57, 4956.

13. Wick, W.; Grimmel, C.; Wagenknecht, B.; Dichgans, J.; Weller, M. J. Pharmacol. Exp. Ther. 1999, 289, 1306.

14. Zuco, V.; Supino, R.; Righetti, S. C.; Cleris, L.; Marchesi, E.; Passerini, C. G.; Formelli, F. Cancer Lett. 2002, 175, 17.

15. Eiznhamer, D. A.; Xu, Z.-Q. IDrugs 2004, 7, 359.

16. Development therapeutics program national cancer institute/national institutes of health, B., MD, USA. http://dtp.nci.nih.gov/dtpstandars/ cancerscreeningdata/index.jsp.

17. Cichewicz, R. H.; Kouzi, S. A. Med. Res. Rev. 2004, 24, 90.

18. Kvasnica, M.; Sarek, J.; Klinotova, E.; Dzubak, P.; Hadjduch, M. Bioorg. Med. Chem. 2005, 13, 3447.

19. Sarek, J.; Kvasnica, M.; Urban, M.; Klinot, J.; Hajduch, M. Bioorg. Med. Chem. Lett. 2005, 15, 4196.

20. Shintyapina, A. B.; Shults, E. E.; Petrenko, N. I.; Uzenkova, N. V.; Tolstikov, G. A.; Pronkina, N. V.; Kozhevnikov, V. S.; Pokrovsky, A. G. Russ. J. Bioorg. Chem. 2007, 33, 579.

21. Kim, D. S. H. L.; Pezzuto, J. M.; Pisha, E. Bioorg. Med. Chem. Lett. 1998, 8, 1707.

22. Jeong, H. J.; Chai, H. B.; Park, S. Y.; Kim, D. S. H. L. Bioorg. Med. Chem. Lett. 1999, 9, 1201.

23. Kim, J. Y.; Koo, H.-M.; Kim, D. S. H. L. Bioorg. Med. Chem. Lett. 2001, 11, 2405.

24. Flekhter, O. B.; Karachurina, L. T.; Nigmatullina, L. R.; Sapozhnikova, T. A.; Baltina, L. A.; Zarudii, F. S.; Galin, F. Z.; Spirikhin, L. V.; Tolstikov, G. A.; Plyasunova, O. A.; Pokrovskii, A. G. Russ. J. Bioorg. Chem. 2002, 28, 494.

25. Hata, K.; Hori, K.; Takahashi, S. J. Nat. Prod. 2002, 65, 645.

26. Baglin, I.; Poumaroux, A.; Nour, M.; Tan, K.; Offer, A. C. M.; Dubois, M. A. L.; Chauffert, B.; Cavé, C. J. Enzyme Inhib. Med. Chem. 2003, 18, 111.

27. Hata, K.; Hori, K.; Ogasawara, H.; Takahashi, S. Toxicol. Lett. 2003, $143,1$.

28. Mukherjee, R.; Jaggi, M.; Siddiqui, M. J. A.; Srivastava, S. K.; Rajendran, P.; Vardhan, A.; Burman, A. C. Bioorg. Med. Chem. Lett. 2004, 14, 4087.

29. Mukherjee, R.; Jaggi, M.; Rajendran, P.; Srivastava, S. K.; Siddiqui, M. J. A.; Vardhan, A.; Burman, A. C. Bioorg. Med. Chem. Lett. 2004, 14, 3169.

30. Mukherjee, R.; Jaggi, M.; Rajendran, P.; Siddiqui, M. J. A.; Srivastava, S. K.; Vardhan, A.; Burman, A. C. Bioorg. Med. Chem. Lett. 2004, 14, 2181.

31. Uzenkova, N. V.; Petrenko, N. I.; Shakirov, M. M.; Shul'ts, E. E.; Tolstikov, G. A. Chem. Nat. Compd. 2005, 41, 692.

32. Sorokina, I. V.; Tolstikova, T. G.; Zhukova, N. A.; Petrenko, N. I.; Uzenkova, N. V.; Shul'ts, E. E.; Popova, N. A. Bull. Exp. Biol. Med. 2006, 142, 69.

33. Gauthier, C.; Legault, J.; Lebrun, M.; Dufour, P.; Pichette, A. Bioorg. Med. Chem. 2006, 14,6713 .

34. Urban, M.; Sarek, J.; Kvasnica, M.; Tislerova, I.; Hajduch, M. J. Nat. Prod. 2007, 70, 526.

35. Rajendran, P.; Jaggi, M.; Singh, M. K.; Mukherjee, R.; Burman, A. C. Invest. New Drugs 2008, 26, 25.

36. Kumar, V.; Rani, N.; Aggarwal, P.; Sanna, V. K.; Singh, A. T.; Jaggi, M.; Joshi, N.; Sharma, P. K.; Irchhaiya, R.; Burman, A. C. Bioorg. Med. Chem. Lett. 2008, 18, 5058.

37. Liby, K.; Honda, T.; Williams, C. R.; Risingsong, R.; Royce, D. B.; Suh, N.; Dinkova-Kostova, A. T.; Stephenson, K. K.; Talalay, P.; Sundararajan, C.; Gribble, G. W.; Sporn, M. B. Mol. Cancer Ther. 2007, 6, 2113.

38. Ray, S.; Chaturvedi, D. Drugs Future 2004, 29, 343.

39. Moreira, V. M. A.; Vasaitis, T. S.; Guo, Z. Y.; Njar, V. C. O.; Salvador, J. A. R. Steroids 2008, 73, 1217.

40. Salvador, J. A. R.; Santos, R. C.; Cascante, M. P.T. Patent App. 20091000049475, 2009.

41. Totleben, M. J.; Freeman, J. P.; Szmuszkovicz, J. J. Org. Chem. 1997, 62, 7319.

42. Tang, Y. Q.; Dong, Y. X.; Vennerstrom, J. L. Synthesis 2004, 2540.

43. Freyne, E.; Raeymaekers, A.; Venet, M.; Sanz, G.; Wouters, W.; De Coster, R.; Van Wauwe, J. Bioorg. Med. Chem. Lett. 1998, 8, 267.

44. Pouget, C.; Fagnere, C.; Basly, J. P.; Habrioux, G.; Chulia, A. J. Bioorg. Med. Chem. Lett. 2002, 12, 2859.

45. Tafi, A.; Costi, R.; Botta, M.; Di Santo, R.; Corelli, F.; Massa, S.; Ciacci, A.; Manetti, F.; Artico, M. J. Med. Chem. 2002, 45, 2720.

46. Njar, V. C. O.; Nnane, I. P.; Brodie, A. M. H. Bioorg. Med. Chem. Lett. 2000, 10, 1905. 
47. Mulvihill, M. J.; Cesario, C.; Smith, V.; Beck, P.; Nigro, A. J. Org. Chem. 2004, 69, 5124.

48. Silva, M. R.; Beja, A. M.; Moreira, V. M.; Santos, R. C.; Salvador, J. A. R. Acta Crystallogr., Sect. E 2007, 63, 04824

49. D'Addona, D.; Bochet, C. G. Tetrahedron Lett. 2001, 42, 5227.

50. Herbez, V.; Fischer, F. Tetrahedron Lett. 2005, 46, 6797.

51. Paul, R.; Anderson, G. W. J. Am. Chem. Soc. 1960, 82, 4596.

52. Anderson, G. W.; Paul, R. J. Am. Chem. Soc. 1958, 80, 4423.

53. Rannard, S. P.; Davis, N. J. Org. Lett. 2000, 2, 2117.
54. Tietze, L. F.; Heinzen, H.; Moyna, P.; Rischer, M.; Neunaber, H. Liebigs Ann. Chem. 1991, 12, 1245.

55. Okamoto, I.; Takeya, T.; Kagawa, Y.; Kotani, E. Chem. Pharm. Bull. 2000, 48 120.

56. Walker, D.; Hiebert, J. D. Chem. Rev, 1967, 67, 153.

57. Urban, M.; Sarek, J.; Klinot, J.; Korinkova, G.; Hajduch, M. J. Nat. Prod. 2004, 67, 1100.

58. Pramanick, S.; Mandal, S.; Mukhopadhyay, S.; Jha, S. Synth. Commun. 2005, 35 2143. 